The University of Southern Mississippi

The Aquila Digital Community

Dissertations

Summer 8-2016

\title{
Assessing U.S. Veterans' Work Role Functioning: Influences of Posttraumatic Stress, Sense of Coherence, and Vocational Identity
}

Lauren Kelly Osborne

University of Southern Mississippi

Follow this and additional works at: https://aquila.usm.edu/dissertations

Part of the Counseling Psychology Commons, and the Social Psychology Commons

\section{Recommended Citation}

Osborne, Lauren Kelly, "Assessing U.S. Veterans' Work Role Functioning: Influences of Posttraumatic Stress, Sense of Coherence, and Vocational Identity" (2016). Dissertations. 377.

https://aquila.usm.edu/dissertations/377

This Dissertation is brought to you for free and open access by The Aquila Digital Community. It has been accepted for inclusion in Dissertations by an authorized administrator of The Aquila Digital Community. For more information, please contact Joshua.Cromwell@usm.edu. 
ASSESSING U.S. VETERANS' WORK ROLE FUNCTIONING: INFLUENCES

OF POSTTRAUMATIC STRESS, SENSE OF COHERENCE, AND VOCATIONAL IDENTITY

by

Lauren Kelly Osborne

\begin{abstract}
A Dissertation
Submitted to the Graduate School and the Department of Psychology at The University of Southern Mississippi in Partial Fulfillment of the Requirements for the Degree of Doctor of Philosophy
\end{abstract}

Approved:

Dr. Emily Bullock-Yowell, Committee Chair Associate Professor, Psychology

Dr. Michael Madson, Committee Member Associate Professor, Psychology

Dr. Richard Mohn, Committee Member

Associate Professor, Educational Studies and Research

Dr. Bonnie Nicholson, Committee Member

Associate Professor, Psychology

Dr. Karen S. Coats

Dean of the Graduate School 


\section{COPYRIGHT BY}

Lauren Kelly Osborne

2016

Published by the Graduate School

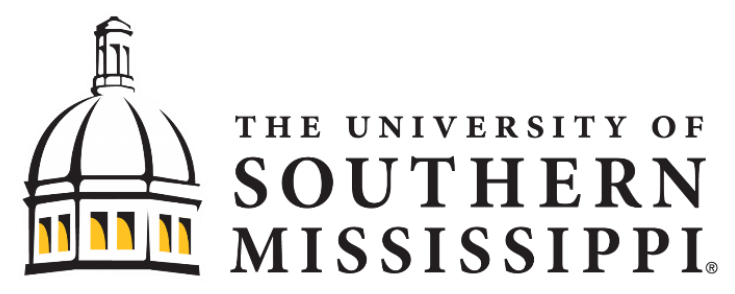




\begin{abstract}
ASSESSING U.S. VETERANS’ WORK ROLE FUNCTIONING: INFLUENCES OF POSTTRAUMATIC STRESS, SENSE OF COHERENCE,
\end{abstract} AND VOCATIONAL IDENTITY

by Lauren Kelly Osborne

August 2016

Since the beginning of military operations in Iraq and Afghanistan following the September 11, 2001 terrorist attacks that now characterize the Operation Iraqi Freedom (OIF) and Operation Enduring Freedom (OEF) combat eras, unique stressors and conditions have faced service members. Advancements in military medicine have resulted in greater survival rates of combat veterans but have also increased rates of chronic psychological distress (Schnurr, Lunney, Bovin, \& Marx, 2009). Research regarding these concerns has increased as these service members are now returning home and re-entering civilian life, and many studies show the detrimental effects of service on psychosocial functioning following combat including employment difficulties. As unemployment among veterans has dropped since the beginning of 2013 (U.S. Department of Labor, 2014), understanding how veterans are functioning in their new civilian work roles is the next step in better understanding their unique experiences of transitions (Strauser, Lustig, Cogdal, \& Uruk, 2006). This study assessed the relationship between PTSS and current work role functioning among OIF and OEF veterans, including evaluation of the influence of personal variables such as reports of sense of coherence and vocational identity. Results of the study found PTSS and sense of coherence to predict work role functioning and PTSS to predict vocational identity in line 
with hypotheses. Further, sense of coherence was found to mediate the relationship between PTSS and work role functioning in support of hypotheses. Results indicate that sense of coherence does not moderate the relationship between PTSS and work role functioning, nor does it moderate the relationship between PTSS and vocational identity. Additionally, vocational identity was not found to moderate the relationship between PTSS and work role functioning. Clinical implications, limitations, and directions for future research are addressed. 


\section{TABLE OF CONTENTS}

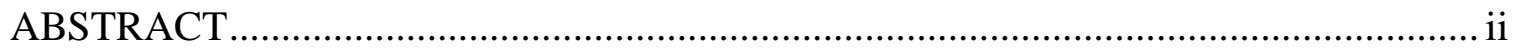

LIST OF TABLES ...................................................................................... vi

LIST OF ILLUSTRATIONS .......................................................................... vii

LIST OF ABBREVIATIONS ........................................................................... viii

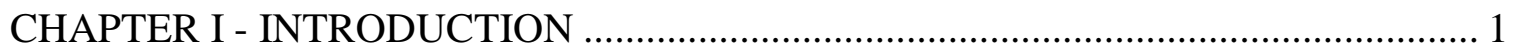

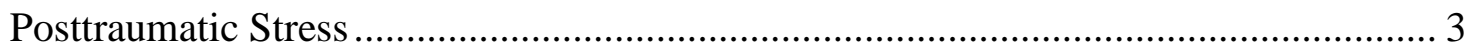

Posttraumatic Stress and Associated Functioning ........................................... 5

Posttraumatic stress and resilience.......................................................... 7

Work Role Functioning................................................................................ 9

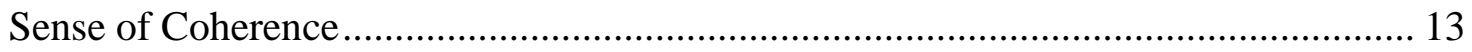

Sense of Coherence and Stress Reactions.......................................................... 16

Sense of Coherence and Work ....................................................................... 20

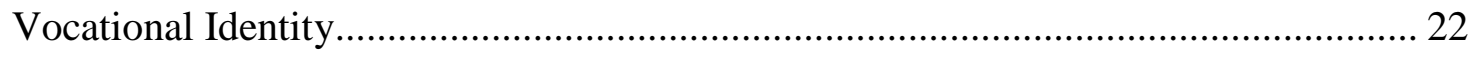

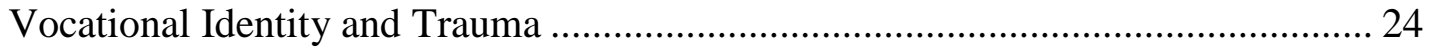

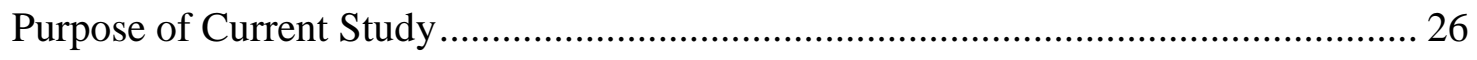

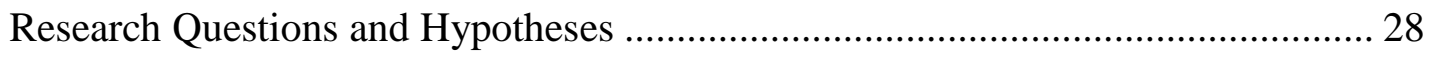

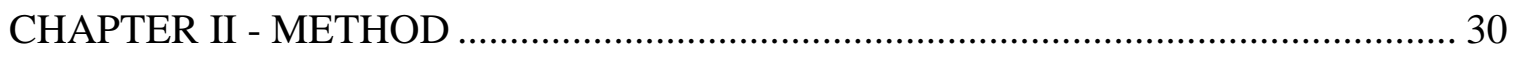

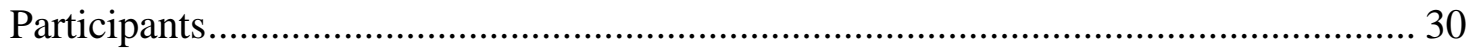

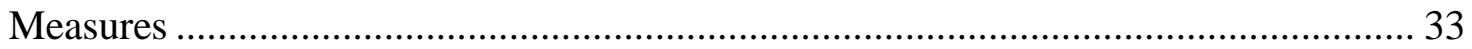


Demographic Questionnaire

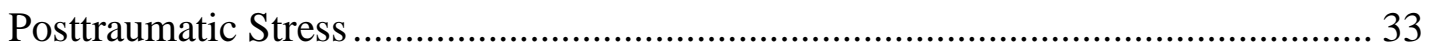

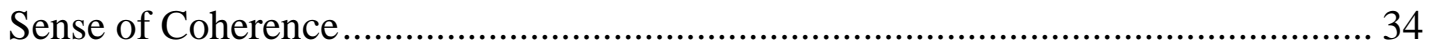

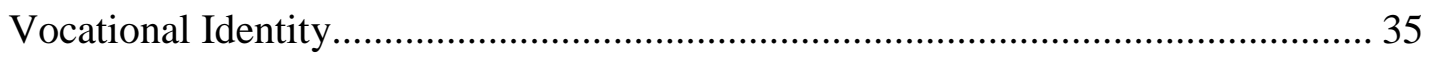

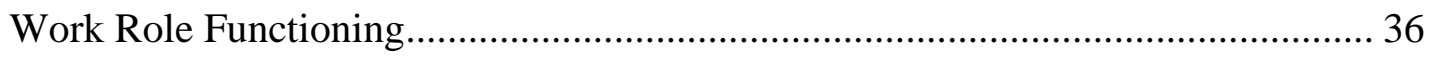

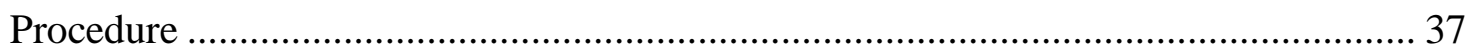

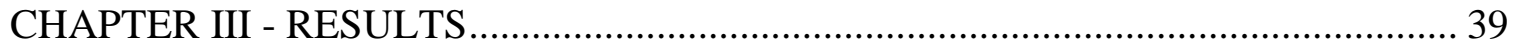

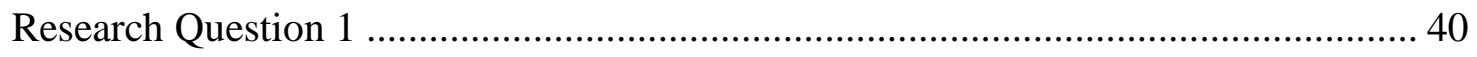

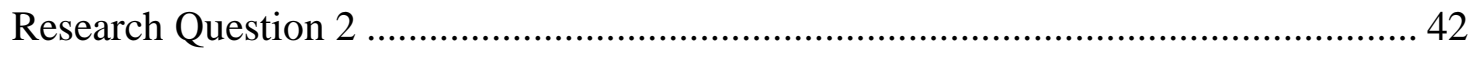

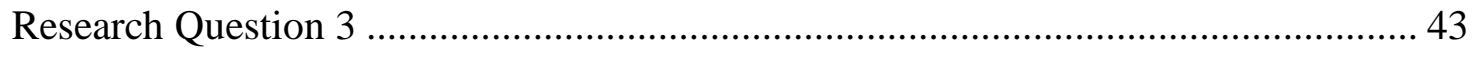

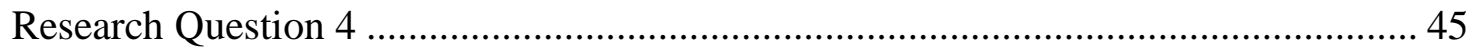

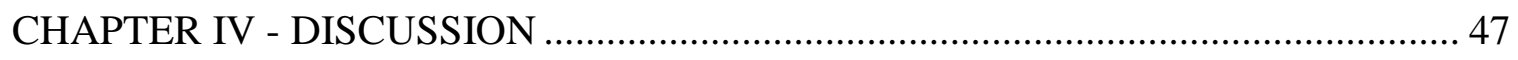

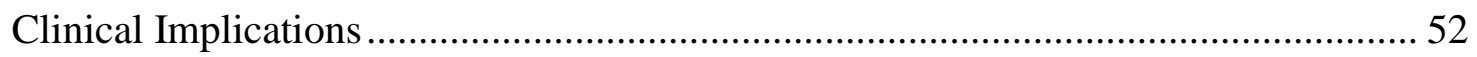

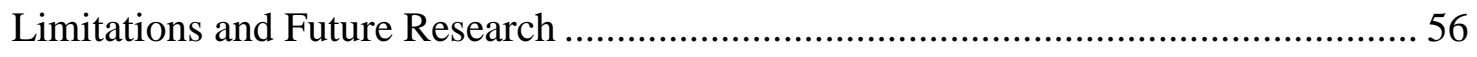

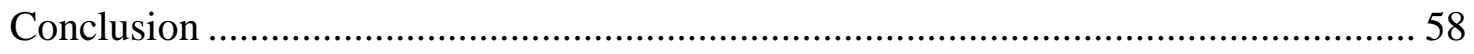

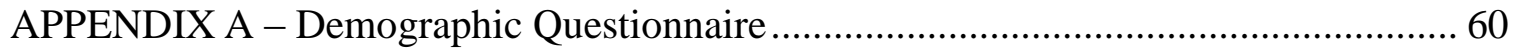

APPENDIX B - Institutional Review Board Approval Letter ..................................... 64

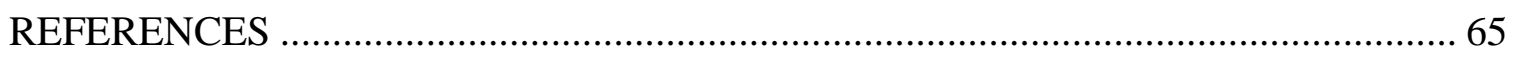




\section{LIST OF TABLES}

Table 1 Demographic Characteristics of the Sample ..................................................... 31

Table 2 Means, Standard Deviations, and Correlations ............................................. 39

Table 3 Summary of Regression for Work Role Functioning .................................... 45

Table 4 Summary of Regression for Vocational Identity ....................................... 46 


\section{LIST OF ILLUSTRATIONS}

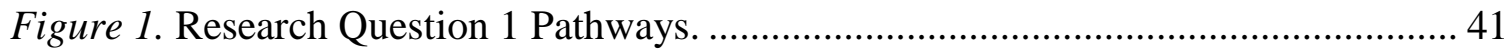

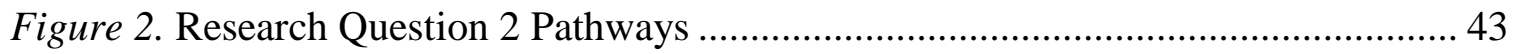




\section{LIST OF ABBREVIATIONS}

DSM-IV-TR

OIF

$O E F$

PTSD

PTSS

ROTC

SOC

TBI

$V I$

$W R F$
Diagnostic and Statistical Manual-Fourth Edition-Text Revision

Operation Iraqi Freedom

Operation Enduring Freedom

Posttraumatic Stress Disorder

Posttraumatic Stress Symptoms

Reserve Officer Training Corps

Sense of Coherence

Traumatic Brain Injury

Vocational Identity

Work Role Functioning 


\section{CHAPTER I - INTRODUCTION}

Following the terrorist attacks of September 11, 2001, the United States engaged in military operations that characterize the current Operation Iraqi Freedom (OIF; serving in Iraq) and Operation Enduring Freedom (OEF; serving in Afghanistan) combat era. Nearly two million American service members have been deployed to Iraq and Afghanistan with almost 700,000 individuals having transitioned out of service since these operations began (Ainspan, 2011). OIF and OEF combat conditions are unique in their contribution to and promotion of the development of posttraumatic psychological and physical difficulties among service members (Schnurr et al., 2009). While military medicine and service capabilities have increased the rate of survival among those wounded in battle, they have also increased the prevalence of blast-related injuries including traumatic brain injury (TBI) and chronic psychological concerns (Schnurr et al., 2009).

Psychological concerns have been at the forefront of discussions regarding veterans returning home from the most recent conflicts in Iraq and Afghanistan with some studies reporting that $10-15 \%$ of returning veterans meet criteria for a diagnosis of posttraumatic stress disorder (PTSD; Erbes, Westermeyer, Engdahl, \& Johnson, 2007; Gewirtz, Polusny, DeGarmo, Khaylis, \& Erbes, 2010; Hourani et al., 2012; Milliken, Auchterlonie, \& Hoge, 2007; Renshaw 2011). Others have reported rates of positive screening for PTSD, TBI, and/or depression as high as 30\% among OEF and OIF veterans (Ainspan, 2011; Rudstam, Gower, \& Cook, 2012). PTSD and TBI have been characterized as the "signature injuries" of the wars in Iraq and Afghanistan and as such 
have garnered much attention in research and treatment (Ainspan, 2011; Keane, 2008; Rosenfeld et al., 2013; Rudstam et al., 2012).

As OEF and OIF veterans continue to return home in large numbers, a perfect storm faces them with prolonged economic and employment decline coupled with an increasing population of veterans with invaluable experiences and work values (Zivin et al., 2012). In conjunction with these factors, misconceptions among the civilian employers about military service further translate into difficulty finding and maintaining employment following service disengagement for many veterans (Ainspan, 2011). The foundation that military service provides for civilian work is often underestimated by veterans, and accommodation needs for veterans with disabilities are overestimated by civilian employers which may contribute to difficult work transitions for OEF and OIF veterans (Ainspan, 2011; Rudstam et al., 2012).

Successful transitions to civilian life are often influenced, by obtaining civilian employment. For veterans, gaining civilian employment has been found to be associated with increased self-efficacy, social support, psychosocial functioning, and overall satisfaction with life (Ainspan, 2011; Spiegel \& Shultz, 2003; Zivin et al., 2012). Zivin et al. (2012) highlighted the impact of depression on employment among working age veterans and the impact of changes in depression status on continued employment. Researchers have called for more research and policy attention to specific areas of veteran mental health and employment, and specifically the potential buffering effects of employment variables for mental health when considering employment outcomes and performance (Zivin et al., 2012). Attention to career barriers and employment concerns, especially among those veterans returning from current conflicts, is critical in improving 
transitions and quality of life for our service members facing barriers to successful immersion in civilian life (Ainspan, 2011; Bullock, Braud, Andrew, \& Phillips, 2009; Haynie \& Shepherd, 2011; Smith, Schnurr, Rosenheck, \& Salzer, 2005; Spiegel \& Shultz, 2003). Therefore, the current study sought to examine the relationship between the mental health concerns plaguing OEF and OIF veterans, specifically posttraumatic stress symptoms (PTSS), and work functioning following transition out of service to the civilian workforce by evaluating the influences of vocational identity and sense of coherence.

\section{Posttraumatic Stress}

High intensity combat situations have become the normal experience of OEF and OIF service members and are characterized as the most severe stressor for these men and women (Kennedy, Leal, Lewis, Cullen, \& Amado, 2010). With the ongoing potential of life threatening experiences during deployment, PTSD rates have been reported at approximately twice that of the general population. Some reports indicate $12-20 \%$ prevalence in OEF and OIF troops compared to the reported $7-8 \%$ in the general population (Kennedy et al., 2010). Further, for military populations that have not been deployed, this rate is reportedly even lower at 5\% (Kennedy et al., 2010).

Longitudinal investigations of OEF and OIF veterans' reported PTSS have provided evidence for increases in psychological suffering as veterans move further away from their return date (Gewirtz et al., 2010; Hourani et al., 2012; Milliken et al., 2007). Milliken et al. (2007) examined reported PTSS among more than 88,000 veterans returning from Iraq as part of a post-deployment health assessment. Assessment of veterans occurred immediately following return from deployment and at 3-6 months post 
return (Milliken et al., 2007). In this case, PTSS, depression, and overall mental health risk were noted to have substantially increased among both active duty and reservists across this time period (Milliken et al., 2007). Reported PTSS increased from 11.8\% to $16.7 \%$ among active duty veterans and from $12.7 \%$ to $24.5 \%$ among reservists with more than twice as many new cases of significant PTSS reported among soldiers who did not initially identify significant concerns (Milliken et al., 2007). Interestingly however, both active and reserve soldiers reported similar rates of combat experiences that may qualify as traumatic, 69\% and 66.5\%, respectively (Milliken et al., 2007).

Renshaw (2011) investigated factors associated with PTSS and the contributors to development of symptoms, including combat experiences, post-battle experiences (e.g. seeing wounded individuals or handling dead bodies), and perceptions of threat. Results indicated that the three factors were strongly correlated with one another and with reported severity of PTSS (Renshaw, 2011). Further, perceived threat was found to moderate the relationship between combat experience and PTSS, while post-battle experiences had a direct and significant effect on PTSS (Renshaw, 2011). This suggests that combat experiences and post-battle experiences contribute in distinct ways to the development of PTSS (Renshaw, 2011). In one study of National Guard Soldiers, Gewirtz and colleagues (2010) measured PTSS twice in the same sample. The first measurement was taken in the theater of war and the second at one year following the soldiers' return home. Here, researchers found that at time one, $6 \%$ of soldiers reported PTSS symptoms that met criteria for PTSD and at time two, this number rose to $15 \%$ with medium to large effect sizes noted (Gewirtz et al., 2010). 
More recent studies have illustrated the complicated etiology of PTSD in returning veterans. In an investigation of 475 marines leaving military service, PTSD was assessed upon return from deployment and again six months following return to civilian life (Hourani et al., 2012). Analysis revealed a 3\% drop in PTSD rates among marines that initially reported clinically significant symptoms while an additional $10 \%$ met screening criteria for PTSD at follow up that did not at baseline (Hourani et al., 2012). Further, post-separation stress was found to be the strongest predictor of mental health problems, both new and chronic, with financial and unemployment stress contributing the greatest amount of stress (Hourani et al., 2012).

\section{Posttraumatic Stress and Associated Functioning}

While acknowledgment of PTSD prevalence among current OEF and OIF era war veterans is increasing among both the civilian and military research communities, examination of impairments associated with symptoms of post-traumatic stress continues to require attention. In an evaluation of $117 \mathrm{OEF} / \mathrm{OIF}$ veterans enrolled in health care at a Veterans Affairs Medical Center, 12\% of veterans screened positive for PTSD and 33\% reported symptoms of problematic alcohol use (Erbes et al., 2007). Further, Erbes and colleagues (2007) found both PTSD and alcohol abuse to be associated with lower quality of life across multiple domains, independent of depression symptoms. Veterans who reported increased PTSS also reported more impairment in emotional, physical, and social roles and reported more limitations and general health concerns (Erbes et al., 2007). In a sample of more than 4,000 veterans returning from combat operations in Iraq and Afghanistan, 30-31\% reported clinically significant PTSS and depression with those associated with OIF combat reporting more PTSS than those associated with OEF combat 
(Lapierre, Schwegler, \& LaBauve, 2007). Further, among all veterans in this study that reported significant PTSS, they also reported more depression symptoms and less overall satisfaction with life (Lapierre et al., 2007).

In effort to further research regarding long-term effects of PTSS among OEF and OIF veterans, many researchers have begun to focus on the functional impact of such mental health concerns. Previous literature examining veterans from the Vietnam era have shown differences among those with PTSD and those without the diagnosis to be significant. Jordan et al.'s (1992) results indicate that male Vietnam veterans with PTSD were five times less likely than those without PTSD to be employed. More recent research has suggested continued functional impairment, such as difficulty in fulfilling social, personal, and/or occupational demands, among veterans with significant PTSS (Breslau, Lucia, \& Davis, 2004; Hourani et al., 2012; Pietrzak et al., 2010; Rona et al., 2009; Stein et al., 2000). Hourani et al. (2012) reported that up to $10 \%$ of their 475 participants noted functional impairment after separating from service, indicating that mental health concerns kept them from completing daily activities. Further, in examination of the relationships between functional difficulties and symptom clusters of PTSD in $272 \mathrm{OEF}$ and/or OIF veterans, all symptoms in addition to combat exposure and dysphoria, were found to be significantly and positively correlated with reported work difficulties, psychosocial difficulties, and family difficulties (Pietrzak, Goldstein, et al., 2010).

Examinations of associated psychosocial impairment have also begun to garner attention. In one study, Breslau and colleagues (2004) found PTSS in civilians to be significantly associated with increased loss of work. Similarly, previous research has 
shown evidence of primary care patients diagnosed with PTSD missing more work days and reporting reduced productivity compared to patients without mental health diagnoses (Stein et al., 2000). In one study conducted with more than 2,800 veterans one year following their return from Iraq, 16.6\% reported significant PTSS with increased rates of PTSS among those with injuries from combat (Hoge, Terhakopian, Castro, Messer, \& Engel, 2007). Further, Hoge and colleagues (2007) found that combat veterans with clinically significant PTSS also exhibited higher rates of sick calls and were more likely to have missed more than one day of work over the previous month. In Rona et al.'s 2009 study, functional impairment among UK Military veterans with reported PTSS was found to be associated with increased symptomology. More specifically, symptoms of avoidance and numbing were most strongly and consistently associated with work impairment followed by hyperarousal symptoms (Rona et al., 2009). Further, overall reported PTSS were significantly and positively associated with both social and work impairment (Rona et al., 2009).

Posttraumatic stress and resilience. Following the surge in research aimed at understanding the development and effects of PTSS among OEF and OIF veterans, it is critical to also evaluate factors that may aid in buffering effects of combat on these individuals. In their longitudinal study of mental health among marines, Hourani et al. (2012) sought to characterize the influences of resilience factors such as self-esteem, optimism, and perceived control. Results indicated that pre-separation resilience was inversely related to the likelihood of respondents experiencing chronic mental health problems and those with higher resiliency scores conferred an $85 \%$ chance of reporting no mental health concerns (Hourani et al., 2012). Further, resilience was found to be 
associated with mental health and functional impairment, suggesting that resilience factors may allow an individual to maintain functionality despite mental health concerns (Hourani et al., 2012).

In an effort to better understand how resilient OEF and OIF veterans may differ from those with significant PTSS, Pietrzak and Southwick (2011) examined demographic and psychosocial differences between these two groups. After surveying $272 \mathrm{OEF}$ and OIF veterans, Pietrzak and Southwick (2011) found that those with significant PTSS were younger and less likely to be married or living with a partner. Further, resilient veterans were more likely to be active duty rather than a reservist or National Guard soldier and to report higher levels of perceived purpose and control than those with PTSD (Pietrzak \& Southwick, 2011). In examination of work, family, peer, and financial functioning among these two groups, those in the PTSD group reported significantly higher levels of difficulties in these areas (Pietrzak \& Southwick, 2011). In an earlier study, Pietrzak, Johnson, and colleagues (2010) found resilience to partially mediate the relationship between unit support and PTSS and depressive symptoms. In veterans with significant PTSS and depressive symptoms, resilience was noted to provide a buffering effect for psychosocial difficulties, such as work and financial difficulties (Pietrzak, Johnson, et al., 2010).

Investigations into the effects of PTSS on individuals' overall functioning continue to be an area of interest for many researchers. As it has been well established in the literature that PTSS is associated with work difficulties and functional impairment (Hoge et al., 2007; Hourani et al., 2012; Pietrzak et al., 2010; Rona et al., 2009; Stein et al., 2000), the current study sought to investigate this relationship further. Evaluation of 
the influence of resilience factors that may buffer psychosocial difficulties as suggested by Pietrzak, Johnson et al. (2010) will be the focus of the proposed study with a deeper look at the path from PTSS to functional impairment in civilian work roles.

\section{Work Role Functioning}

The influence of mental health diagnoses on functioning in the work force has long been a topic of vocational and general mental health research (Dixon, Goldberg, Lehman, \& McNary, 2001; Michon et al., 2008; Wallner \& Clark, 1989). Functioning of individuals in work roles is increasingly gaining interest (Abma, Amick, van der Kling, \& Bultmann, 2013; Erbes, Kaler, Schult, Polusny, \& Arbisi, 2011; Hogh \& Mikkelsen, 2005; Power \& Hershenson, 2003) where previous research has only utilized employment status as a measure of impairment. Most recent reports from the U.S. Department of Labor indicate lower unemployment rates among U.S. veterans than non-veterans as of March, 2016 (4.5 and 5.0 respectively; U.S. Department of Labor, 2016). These discrepancies indicate that understanding the current functioning of those veterans who have gained employment may provide invaluable information for practitioners and researchers

Griffin and Hesketh (2003) proposed that adaptive work performance consisted of eight dimensions of performance including proactive, reactive, and tolerance behaviors. Adaptability and flexibility are key competencies for workers today, and preparing for changes in current work or transitions to new work-roles is part of the adaptive orientation of performance (Griffin \& Hesketh, 2003). In examination and testing of this taxonomy among military personnel, past experiences and self-efficacy for adaptable behavior were found to be related to adaptive performance (Griffin \& Hesketh, 
2003). Erbes et al. (2011) supported this assertion as they found factors of past experiences such as earlier work role functioning to be as strong a predictor of current functioning as depression symptoms.

Niessen, Binnewies, and Rank (2010) examined the influence of past experiences by evaluating the level of attachment to prior work roles. Researchers postulated that workers can be distracted by a strong psychological attachment to prior jobs which may in turn contribute to poorer functioning in new jobs due to distractibility and possible negative affective influences (Niessen et al., 2010). They found that attachment to, and thus disengagement from, prior work roles play a major part in work adjustment (Niessen et al., 2010). Results suggest that emotional detachment from past jobs can foster positive adaptation and pursuit of learning which may contribute to better fit with new work roles over time (Niessen et al., 2010). Further, if psychological attachment evokes negative emotions such as regret or guilt, as may be the case in individuals experiencing significant PTSS, this may be problematic for adjustment to new work roles (Niessen et al., 2010). Thus, Niessen and colleagues (2010) suggest that overcoming negative influences from prior work roles and experiences is critical for successful performance in new work roles. With this in mind, it is reasonable to expect that emotional connections such as stress reactions from trauma exposure, are likely to hinder functioning in new work roles.

Stress in prior work roles has also been found to be detrimental to task performance, specifically, in new roles (Jimmieson \& Terry, 1998). Research has shown that active memory recall to past experiences can negatively influence task performance and generate distractions from new work role needs (Niessen et al., 2010). Power and 
Hershenson (2003) further support the assertion of influence of past experiences in an examination of individuals with mid-career onset traumatic brain injury. They found that those who reported more emotional investment in their prior job also exhibited more problematic work-adjustment (Power \& Hershenson, 2003). In another study of OEF and OIF veterans, those who reported increased military sexual stressors also reported significantly poorer adjustment to new work roles as well as poorer social and physical functioning (Murdoch, Pryor, Polusny, \& Gackstetter, 2007).

In agreement with Griffin and Hesketh (2003), Niessen et al. (2010) suggested that the influence of other variables on relationships between past experiences and work adjustment such as self-efficacy be evaluated. Power and Hershenson (2003) found many influences on work adjustment among individuals with mid-career onset TBI such as self-concept and ability to cope with obstacles as they are presented. When engaging in new work roles, lowered confidence combined with other psychological barriers can make transitioning to new work roles challenging (Secker, Membrey, Grove, \& Seebohm, 2003). In one study of the general working population, base-line health and work ability were significant prognostic factors for successful work functioning (Abma, Amick, van der Kling, \& Bultmann, 2013). However, as Niessen and colleagues' (2010) research suggests, active disengagement from prior roles should buffer negative impact of emotional reminders and links on new work roles.

Additionally, some researchers have found evidence of significant negative relationships between severity of mental health symptoms and employment variables suggesting that increased severity may result in lower likelihood of employment (Resnick \& Rosenheck, 2008). In a study of veterans participating in a compensated work therapy 
program through the Veterans Health Administration, veterans with PTSD were 19\% less likely to be competitively employed (Resnic \& Rosenheck, 2008). However, more recent research illustrates a more adaptive picture of PTSD.

Erbes et al. (2011) evaluated the relationships between mental health diagnoses and work role functioning over time. Research in civilian populations has suggested that psychological diagnoses may be associated with impairment in work functioning but they do not incapacitate a worker's functional ability (Erbes et al., 2011). Erbes et al. (2011) found PTSS to be uniquely related to decrements in work role functioning over time in areas such as decreased attendance at work and poor job evaluations. As results did not indicate that employment was less likely for individuals with significant psychological symptoms, this study supported previous research which found that employment is not necessarily eroded by psychological disorders (Erbes et al., 2011). Instead, it appears that detrimental effects of mental health issues occur more subtly as psychological symptoms have been associated with less frequent promotions and more absences at work (Erbes, et al., 2011).

Researchers suggest that identification of constructs that may facilitate work adjustment is also critical in promoting successful transitions (Strauser \& Lustig, 2003). As such, evaluation of variables that may provide positive influences on work role functioning was evaluated in the current study. Erbes et al. (2011) suggested that functional ability is not completely deteriorated by mental health concerns, and this study took a closer look at what variables may influence the level of work role functioning in OEF and OIF veterans. It is suggested that emotional connections to previous work roles and views of control over life situations may influence how well an individual may 
function in new work roles (Hourani et al., 2012; Niessen et al., 2010; Power \& Hershenson, 2003). Thus, the role that personal factors such as emotional symptoms and views of the world through sense of coherence may play in work role functioning was evaluated in the current study.

\section{Sense of Coherence}

Antonovsky (1987) defined sense of coherence as a global construct that affects how individuals understand the world around them and events that occur. His developed construct consists of three interrelated concepts: comprehensibility, manageability, and meaningfulness (Antonovsky, 1987). Vossler (2012) defines comprehensibility as the belief that internal and external environments are structured, predictable, and explicable and that individuals can make sense of events in one's life. Manageability is defined as the belief that one possesses the resources to meet the demands of the environment and the confidence in one's ability to cope with these stressors (Vossler, 2012). The belief that demands in the world are worthy of investment and may be viewed as a challenge instead of a burden is characterized as meaningfulness (Vossler, 2012). Further, this component of sense of coherence may provide an individual the meaning that promotes putting forth effort to effectively cope with challenging situations (Vossler, 2012).

Many have postulated that sense of coherence is highly related to other protective factors such as resilience, hardiness, and self-efficacy (Almedom, 2005; Antonovsky, 1987) and negatively correlated to burnout, depression, and anxiety (KroningerJungaberle \& Grevenstein, 2013). In Almedom's (2005) literature review, he notes that Antonovsky's development of sense of coherence as a construct was undertaken with similar constructs such as hardiness and self-efficacy in mind. Sullivan (1993) also noted 
the similarities of these factors; but it is asserted that sense of coherence appears to be the more inclusive resilience factor as concepts of hardiness such as control, commitment, and challenge are accounted for by Antonovsky's (1987) concepts of meaningfulness and manageability. Likewise, it is noted that self-efficacy is also conceptually related to these portions of sense of coherence as they are noted to characterize an individual's view that events in the world are under some control and that they may help shape outcomes as well as the belief that making this effort is worthwhile (Sullivan, 1993). Almedom (2005) further asserts that sense of coherence is the preferable construct for use in analyzing such coping and resilience factors as it appears to be inclusive of these related concepts and extends further in evaluation of an individual's sense of the world with the addition of comprehensibility.

In his original conceptualization, Antonovsky (1987) asserted that sense of coherence is a construct developed early in life and is relatively stable across the lifetime. Kroninger-Jungaberle and Grevenstein (2013) tested two developmental hypotheses related to this assertion. One of these hypotheses suggested that sense of coherence fluctuates early in life and remains relatively constant after the age of thirty years and the other suggested that levels of sense of coherence rather than age predicts the stability of the construct (Kroninger-Jungaberle \& Grevenstein, 2013). Results of this study suggest that the foundation of sense of coherence and the resilience it offers is laid in early childhood and tends to be stable by adolescence (Kroninger-Jungaberle \& Grevenstein, 2013). Moksnes, Lohre, and Espnes (2013) echoed these results and further asserted that even at adolescence sense of coherence is associated with life satisfaction. Further, Kroninger-Jungaberle and Grevenstein (2013) postulate from their research that those 
with stronger sense of coherence may experience challenging situations with the expectancy that problems can be dealt with and retain a positive attitude towards ability to respond to life challenges.

Some studies however, suggest moderate stability in sense of coherence in both males and females. Kivimaki, Vahtera, Elovainio, Lillirank, and Kevin (2002) found that violence and financial difficulty were associated with decreases in sense of coherence over time for males, while Feldt, Leskinen, Kinnunen, and Ruoppila (2003) showed that age did not influence changes in sense of coherence. In an earlier study, Schnyder, Buchi, Sensky, and Klaghofer (2000) investigated sense of coherence among accident victims. Participants exhibited significant decreases in sense of coherence in the first six months following respective accidents but stabilized in the second six months (Schnyder et al., 2000). Further, measures of sense of coherence exhibited high test-retest reliability and appeared to support the view of this construct as a relatively stable trait in Schnyder and colleagues' (2000) study.

It is asserted that results suggest that sense of coherence is an independent measure of a person's world view which may be influenced by experienced traumatic events but should be considered a stable trait (Schnyder et al., 2000). Sarenmalm, Browall, Persson, Dall-Dickson, and Gaston-Johansson (2013) also suggest that sense of coherence may develop over the entire lifetime and that all experiences continue to influence associated beliefs. However, should sense of coherence remain stable and strong, Antonovsky (1987) asserted that this would provide the individual with increased ability to cope with psychosocial stressors in their environment and thus in their work environment (Hogh \& Mikkelsen, 2005). 


\section{Sense of Coherence and Stress Reactions}

Research has shown that sense of coherence appears to play a major role in coping across stressful situations (Sarenmalm et al., 2013). Gana (2001) examined the role of sense of coherence in psychological well-being through investigation of effects of adversity. As research has noted sense of coherence as a resiliency factor, Gana (2001) asserted that this construct should mediate the relationship between mental health concerns such as anxiety, worry, and stress, and overall satisfaction with life. Results supported this assertion as sense of coherence was found to fully mediate this relationship and was further suggested to exhibit buffering effects (Gana, 2001). That is, those that reported having a weak sense of coherence appear to be more vulnerable to stressful experiences (Gana, 2001).

In examination of stress reactions in individuals exposed to violence at work, Hogh and Mikkelsen (2005) investigated the role of sense of coherence between these variables. In a sample of 1,857 Danish adults, employees subjected to work violence reported more stress reactions and a weaker sense of coherence than those that were not exposed (Hogh \& Mikkelsen, 2005). Stress reactions included reported psychosomatic stress such as dizziness and muscular tension as well as cognitive stress such as concentration and memory difficulties (Hogh \& Mikkelsen, 2005). Psychological stress reactions, including symptoms of depression and nervousness were also evaluated by the researchers (Hogh \& Mikkelsen, 2005). Sense of coherence was found to have mediated the relationship between violence and psychosomatic and cognitive stress reactions (Hogh \& Mikkelsen, 2005). This 2005 study by Hogh and Mikkelson provided evidence that sense of coherence is a key component of the relationship between work violence 
and stress reactions. Moderating effects of sense of coherence were also investigated; however evidence for this relationship among the previously mentioned variables did not prove significant (Hogh \& Mikkelsen, 2005). Hogh and Mikkelsen (2005) assert that when shown to have a strong sense of coherence, individuals are less likely to feel threatened by violence and report feeling less vulnerable after its occurrence. Some have also noted sense of coherence to have main, moderating, and mediating effects on the relationship between work environment and stress reactions such as behavioral, psychological, and physiological responses to work stress (Albertsen, Nielsen, \& Borg, 2001). However, in Alberstsen et al.'s (2001) earlier study, sense of coherence was found to have mediating effects on more relationships of stress and biopsychosocial responses than moderating effects.

Further, sense of coherence has been linked to general psychological well-being. Wiesmann and Hannich (2013) investigated the role of sense of coherence in the relationships between resistance resources (i.e. social support, self-esteem, physical health, completion of daily activities). Researchers found sense of coherence to significantly predict both general life satisfaction and satisfaction with health (Wiesmann \& Hannich, 2013). Additionally, results found that sense of coherence partially mediated the relationship between these constructs, as well, while fully moderating the relationship between social support and satisfaction with health (Wiesmann \& Hannich, 2013). It is postulated that the resources assessed here facilitate life experiences that lead to stronger sense of coherence in adulthood which may determine the stability and subjective expression of an individual's quality of life (Wiesmann \& Hannich, 2013). 
In other examinations of relationships of sense of coherence and well-being, Zeidner \& Aharoni-David (2015) explored the relationship between sense of coherence, memories of traumatic events, and subjective well-being in late life of Holocaust survivors. Among the 106 survivors included in the study, through thorough interviews and objective measures of well-being and sense of coherence, researchers found evidence for effects of sense of coherence on well-being (Zeidner \& Aharoni-David, 2015). Specifically, sense of coherence was found to have indirect effects on adaptive outcomes in their relationship with traumatic experiences (Zeidner \& Aharoni-David, 2015). Zeidner and colleagues (2015) asserted that the salutogenic perspective touted by Antonovsky is consistent with their findings and that internal strength and established coping strategies lead to a better overall sense of mental health and well-being in late life. Thus, further support is provided for the long-lasting benefits of strengthened sense of coherence on well-being.

Sense of coherence has also been found to be a significant predictor of distress, health status, and quality of life in a group of women diagnosed with breast cancer (Sarenmalm et al., 2013). In a study of individuals diagnosed with serious mental illness, sense of coherence was found to independently predict the psychosocial impact of the associated stigma (Switaj et al., 2013). Further, in adolescents with congenital heart disease, a strong sense of coherence was associated with increases in perceived health and found to be a consistent predictor of perceived health over time (Aspers, Luyckx, Rassart, Goossens, Budts, \& Moons, 2013). In a survey of middle-aged women that experienced domestic violence, sense of coherence along with social support was found 
to have a protective effect on the relationship between violence and health symptoms (Krantz \& Ostergren, 2000).

In assessment of the role of sense of coherence and its relation to PTSS, research has shown significant associations. Dudek and Koniarek (2000) found that among a cohort of firefighters, those with weaker sense of coherence exhibited higher levels of PTSS. Likewise, individuals with chronic posttraumatic stress disorder that reported strong sense of coherence were found to also report lower stress and higher quality of life (Delgado, 2007). Lustig, Strauser, Detrie, Henderson, and Frazier (2001) assert that when the environment does pose a threat to individuals, those with stronger sense of coherence tend to be able to make necessary adjustments to maintain stability and productivity. That is, they are able to continue to maintain optimal functioning despite operating in an environment that is perceived as threatening, and they are able to adjust to perceived threats more effectively (Lustig et al., 2001).

In a recent study that sought to examine resilience and PTSD among paramedics, Streb, Haller, and Michael (2014) investigated the role that sense of coherence played in development of PTSD among 668 paramedics. Researchers found that sense of coherence was a better predictor of symptom severity than resilience as measured by the Resilience Scale (Streb, Haller, \& Michael, 2014). Additionally, receipt of psychological services following work-related traumatic events further helped to reduce symptom severity in this sample (Streb, Haller, \& Michael, 2014). Among 120 Portuguese veterans, similar results were found as sense of coherence served as a mediator in the relationship between abusive violence and PTSD and depression as well as combat exposure and PTSD and depression (Ferrajao \& Oliveira, 2016). In this most recent study, researchers suggested 
that veterans with stronger sense of coherence possessed stronger resources that enabled them to recognize their experiences as manageable and view the world as overall meaningful and predictable (Ferrajao \& Oliveira, 2016).

Sense of Coherence and Work

Research regarding the relationships between sense of coherence and work related variables is sparse, but some evidence for these relationships has been established. In their 2002 study, Lustig and Strauser found a significant negative relationship between sense of coherence and negative career thinking. That is, those that reported a stronger sense of coherence also reported higher levels of negative career thinking (Lustig \& Strauser, 2002). Further, sense of coherence accounted for significant variance among overall negative career thinking and its components including conflict with external influences, confusion about making a career decision, and anxiety regarding committing to a decision (Lustig \& Strauser, 2002).

Strauser and Lustig (2003) later evaluated the relationship between sense of coherence and work adjustment. Researchers defined work adjustment as the interaction of the work environment with work personality and work competency according to Hershenson's model of work adjustment (Strauser \& Lustig, 2003). This included the domains of work personality and competency including task orientation, social skills, work motivation, work conformance, and personal presentation (Strauser \& Lustig, 2003). Sense of coherence was found to be associated with more developed work personalities and better habits at work, coworker relationships, adaptability to work roles, and responses to authority figures with medium to high correlations for all variables (Strauser \& Lustig, 2003). Their results further support the view that higher sense of 
coherence in individuals may promote engagement in behaviors such as initiating activity on the job, learning new tasks quickly, and being able to perform tasks more independently (Strauser \& Lustig, 2003).

Overall, higher levels of sense of coherence appear to have a positive impact on ability to conform to new work rules and promote good judgment in the work environment (Strauser \& Lustig, 2003). Further, these results found that sense of coherence significantly accounted for $18 \%$ of the variance of work personality suggesting that this variable may play a larger role in the response to stressful environments in career-related situations than previously thought (Strauser \& Lustig, 2003). Results revealed that those with stronger sense of coherence were better able to adapt to changing work environments, display better judgment, and respond more appropriately to authority figures (Strauser \& Lustig, 2003). Further, in an investigation of the impact of trauma among Palestinian health providers that served in refugee camps, Veronese and Alessandro (2014) found sense of coherence to serve mediating roles related to social and emotional functioning. Sense of coherence mediated the impact of trauma, including witnessing violence and death, on professionals' ability to manage anxiety and maintain confidence in their abilities to provide services (Veronese \& Alessandro, 2014).

Research continues to support sense of coherence as a notable resource for individuals in situations that result in extreme stress whether they relate to health, work, or experiencing traumatic events (Dudek \& Koniarek, 2000; Hogh \& Mikkelsen, 2005; Lustig et al., 2001). However, researchers have yet to investigate the nature of this construct's role in the work transitions of veterans or those experiencing significant combat trauma. Strauser and Lustig's (2003) research supports the presence of 
significant relationships between sense of coherence and work-related variables suggesting that it may play a role in work functioning. The current study sought to expand this literature as well as evaluate the role that sense of coherence may play when additional stressors such as PTSS are also present. Previous literature has noted the similarity of sense of coherence to constructs such as self-efficacy and hardiness (Almedom, 2005; Sullivan, 1993). However, these researchers also suggest the use of sense of coherence as a more inclusive and efficient way to measure such resilience factors (Almedom, 2005). Thus the current study evaluated sense of coherence as both a mediator and a moderator between PTSS and work role functioning as well as its role in the relationship between PTSS and vocational identity.

Vocational Identity

Vocational identity is defined by Holland, Daiger, and Power (1980) as being the "possession of a clear and stable picture of one's goals, interests, and talents (p. 1191)." Many experts see vocational identity as a developmental construct that is influenced by aspects of the individual and their environment to provide a framework for career development including goal-setting and transitional adjustment (Hirschi, 2012). Mauer and Gysbers (1990) considered vocational identity to be a mixture of personal and emotional issues that develops throughout the lifetime rather than a unitary, unchanging construct. Holland, Daiger, and Power (1980) found that the formation of a more stable vocational identity tends to increase as related variables such as age, training, and specialization also increase. Others' research has reinforced these findings as they confirm that vocational identity is continually influenced by maturity and experience throughout one's lifetime (Stewart, 1994). In a study of 82 Army Reserve Officer 
Training Corps (ROTC) students, career variable differences, including vocational identity were evaluated against a sample of 149 non-ROTC students (Osborne \& Bullock-Yowell, 2011). Here, ROTC students who engaged in specialized training exhibited more stable vocational identities and fewer career decision making difficulties than non-ROTC students and among all students, vocational identity and career decision making difficulties exhibited an inverse relationship (Osborne \& Bullock-Yowell, 2011). This recent research continues to contribute to increased understanding of how vocational identity may be related to other personal variables such as training and decision making abilities.

Vondracek (1992) postulated that development of vocational identity goes through the process of expanding and narrowing options based on personality factors and one's views of the reality of their personal career situation. Shin and Kelly (2013) outlined three key components that contribute to the lifetime development of vocational identity. These include intrapersonal and personality characteristics, relational influences, and social context (Shin \& Kelly, 2013). The inhibition of development of vocational identity has been found to lead to career indecision, role confusion, and negative mental health consequences (Hirschi, 2012; Hirschi \& Lage, 2007; Holland, Gottfredson, \& Power, 1980). Further, positive psychological well-being and increased self-efficacy have been found to be associated with vocational identity development (Shin \& Kelly, 2013).

In an investigation of both American and Korean students, Shin and Kelly (2013) examined the relationship between vocational identity and optimism as defined by the belief that good things generally happen and the ability to take a positive view of events 
and circumstances. They found a significant positive relationship between vocational identity and optimism, which suggests that an individual's view of the world around them and how they interpret life events are related to the development of vocational identity (Shin \& Kelly, 2013). Further, researchers suggest that experiencing positive emotions provides an important positive influence on clarifying one's personal attributes and vocational goals (Shin \& Kelly, 2013).

Investigations of individuals that report characteristics of stable vocational identities have found these individuals to also exhibit high levels of extraversion, emotional stability, conscientiousness, agreeableness, and openness (Hirschi, 2012). Further, vocational identity has exhibited a strong positive correlation with self-efficacy and overall well-being, while exhibiting strong negative correlations with indecisiveness, dysfunctional thinking, and trait anxiety and depression (Hirschi, 2012). In a study of 98 undergraduates, Strauser, Lustig, and Ciftci (2008) found that individuals with higher levels of psychological well-being also exhibited more stable vocational identities, less dysfunctional career thoughts, and more effective work-related behaviors. Vocational identity was also significantly and uniquely influenced by subjects' reported beliefs of having purpose in life (Strauser et al., 2008). Researchers suggest that those who exhibit beliefs that life and events in their world are meaningful will exhibit more stable vocational identities (Strauser et al., 2008).

\section{Vocational Identity and Trauma}

In an earlier study by Strauser et al., (2006), the relationship between trauma symptoms and aspects of career development such as vocational identity were investigated. Coursol, Lewis, and Garrity (2001) had earlier suggested that individual 
functioning in work-related situations may be affected by exposure to traumatic events. Strauser and colleagues' (2006) study further supported this assertion. Strauser et al. (2006) found a significant negative relationship between trauma symptoms and vocational identity among a sample of 131 undergraduates. From these results, the researchers suggest that higher levels of trauma symptoms may impede development of a stable vocational identity (Strauser et al., 2006). Further, in evaluation of work personality relationships with trauma symptoms, Strauser et al. (2006) postulate that those individuals who experience higher levels of trauma symptoms will also exhibit greater use of inappropriate or ineffective behaviors in work environments, thus experiencing decreased work-role functioning. However, Strauser and colleagues (2006) did not investigate current functioning in a work setting and suggest this as the next step in evaluating the relationship of trauma and career variables.

In other research, Haynie and Shepherd (2011) investigated career transitions following traumatic life events in a case study of ten Marines that were discharged from the military due to sustained injuries during combat. In examination of both personal development and occupational role transitions, Haynie and Shepherd (2011) interviewed participants regarding their experiences of career transition. The researchers found that those with less stable career identities transitioned less successfully (Haynie \& Shepherd, 2011). Further, those participants who were able to reestablish meaning and rebuild adaptable assumptions of the world reported more success in pursuits of desired career paths (Hanie \& Shepherd, 2011). It is noted that changes in identity have long been found to accompany career transitions and for service members, perceived limits and 
coping with trauma events may restrict identity adaptation during times of career transitions (Haynie \& Shepherd, 2011).

Strauser et al. (2008) further sought to examine the relationship between psychological well-being and vocational identity. Here, researchers found that vocational identity stability was linked to effective job finding behaviors, and less dysfunctional career thinking (Strauser et al., 2008). Further, purpose in life appeared to have a unique influence on vocational identity with psychological well-being having a medium effect on vocational identity (Strauser et al., 2008). Strauser and colleagues (2008) further proposed that individuals with a more stable vocational identity will also likely hold beliefs that life has meaning and directionality.

Vocational identity has been a core construct of career-related research for many years, but its relationship to trauma is just beginning to be understood. The current study continued this trend started by researchers such as Strauser et al. (2006) and Haynie and Shepherd (2011) by continuing to find the links that may exist among these constructs. Further, as noted by Strauser and colleagues (2008), individual characteristics such as perceived control and meaning in related events appear to also play a role in the stability of vocational identity. Thus, the relationship between these concepts as accounted for by sense of coherence and vocational identity is also of interest to the current study especially as it relates to the further investigation of the relationship among trauma and vocational identity as established by Strauser and colleagues (2006).

\section{Purpose of Current Study}

The current study aimed to further investigate work role functioning among OEF and OIF veterans who have disengaged from military service and transitioned to the 
civilian workforce or into the classroom. First, the current study sought to further understand the influences of PTSS on work role functioning. Previous research has found increased impairment in several areas including social, emotional, physical, and occupational among both civilians and veterans exhibiting significant PTSS (Breslau et al., 2004; Erbes et al., 2007; Erbes et al., 2011; Hoge et al., 2007; Pietrzak, Goldstein, et al., 2010; Rona et al., 2009; Stein et al., 2000; Strauser et al., 2006). Thus the predictive nature of PTSS in relation to work role functioning among OEF and OIF veterans was evaluated in the current study.

Research involving sense of coherence has provided mixed information regarding its role as a mediator or moderator. In relationships between significant stressors and psychopathology, social and emotional functioning, or biopsychosocial responses, sense of coherence has been found to primarily mediate these relationships (Albertsen et al., 2001; Ferrajao \& Oliveira, 2016; Veronese et al., 2014). Others have found sense of coherence to moderate relationships among resources such as social support and satisfaction with health (Wiesmann \& Hannich, 2013). Additionally, sense of coherence has previously been characterized in research as a resilience factor and found to be highly related to constructs of resilience such as self-efficacy, perceived control, and hardiness (Almedom, 2005; Antonovsky, 1987; Kroninger-Jungaberle \& Grevenstein, 2013). Such concepts have been found to be associated with improved work-related functioning among civilian populations (Strauser \& Lustig, 2003), and thus the current study sought to link sense of coherence and current work-role functioning among veterans. Specifically, the role that sense of coherence plays in the relationship between PTSS and work role functioning was examined. The current study examined sense of coherence as a 
mediator in this relationship and evaluated whether it also serves as a moderator. With mixed evidence regarding the role that sense of coherence may play here, both functions were evaluated. Through examination of the potential for sense of coherence to influence the relationship of symptoms and functioning, the current study aimed to clarify if sense of coherence may better serve as a way to improve interventions, in the case of mediation. Likewise, if sense of coherence is found to moderate the relationship between symptoms and functioning, those who may benefit from interventions may be better identified.

To further evaluate career related variables among OEF and OIF veteran populations, the current study also examined the stability of vocational identity among these individuals. Prior research has established positive correlations between vocational identity and psychological well-being, self-efficacy, and optimism while exhibiting negative relationships with anxiety, depression, and trauma symptoms (Hirschi, 2012; Shin \& Kelly, 2013; Strauser et al., 2006; Strauser et al., 2008). Thus, the current study investigated the predictive nature of PTSS related to vocational identity and the role that sense of coherence may play in this relationship.

\section{Research Questions and Hypotheses}

1. Do PTSS, sense of coherence, and/or vocational identity predict levels of workrole functioning among OEF and OIF veterans?

a. Higher reported PTSS will be predictive of poorer work-role functioning.

b. Stronger reported sense of coherence will be predictive of higher workrole functioning. 
c. More stable vocational identity will be predictive of higher work-role functioning.

d. PTSS will predict vocational identity stability and thus have an indirect effect on work role functioning.

2. Does sense of coherence partially mediate the relationship between PTSS and work-role functioning among OEF and OIF veterans?

a. The effect of PTSS on work role functioning will be partially mediated by the addition of sense of coherence.

3. Does sense of coherence moderate the relationship between PTSS and work-role functioning among $\mathrm{OEF}$ and $\mathrm{OIF}$ veterans?

a. The effect of PTSS on work-role functioning will not be moderated by reported sense of coherence.

4. Does sense of coherence moderate the relationship between PTSS and vocational identity among OEF and OIF veterans?

a. The effect of PTSS on vocational identity will vary as a function of reported sense of coherence. 


\section{CHAPTER II - METHOD \\ Participants}

The online survey for the study was viewed 233 times while one hundred eightyeight participants completed at least the consent form and demographic questionnaire. These were displayed before the study measures for all participants that viewed the survey. Of the 188 cases that completed the demographics questionnaire, 31 cases were deleted based on their indication that they did not serve in OEF or OIF combat operations. Due to randomization of the four study measures, missing data occurred at random and the 26 participants that completed three or fewer study measures were not retained in the current data set. The remaining $N=131$ were screened for possible invalid data by two validity items placed throughout the entire survey. Participants that responded incorrectly to one or more of these items were to be removed from the participant pool for analysis. None of the 131 failed more than one validity item placed throughout the survey measures, and thus data was retained from the remaining 131 respondents who met study criteria, completed all study measures, and passed all validity checks. To determine a desired sample size prior to data collection to achieve a desired medium effect size of $f^{2}=.15$, G-power analysis software was utilized. Based on three predictors (PTSS, sense of coherence, and vocational identity), a total sample size of 119 was needed to achieve desired power of .95 .

Participants were 131 male and female veterans that served in both OEF and OIF (i.e. participated in operations in Afghanistan and/or Iraq since 9/11/2001). Respondents identified as maintaining work roles characterized by either working for pay, enrolled as a student, or maintaining a household and having engaged in these roles over the last two 
weeks prior to completing the survey. In the current sample, $74 \%$ of students endorsed attending school, 50\% reported completing housework, and $64.9 \%$ endorsed working for pay. Many participants identified engaging in all three roles over the past two weeks (21.4\%) and nearly half (44\%) indicated engaging in only one role in the last two weeks (12.2\% only working for pay, $19.1 \%$ only attending school, and $2.3 \%$ only completing housework). Demographic characteristics are presented in Table 1. The sample was predominately White, Non-Hispanic (74\%) and had a mean age of 33.65 years. One hundred-four (79.4\%) participants reported being enrolled as a student at the time of the survey, and $66(50.4 \%)$ reported being married. One hundred-fourteen (87\%) respondents indicated that it had been two years or more since their most recent deployment and $31(23.7 \%)$ participants reported having initially enlisted as a reservist. All branches of the U.S. armed services were represented in the current sample with 55 (42\%) participants reporting serving in the U.S. Army. Regarding disability status, 33 (25.2\%) participants reported being service connected for a mental health disorder while 21 of those (16\% of total sample) indicated being service connected for PTSD. Additionally, 67 (51.1\%) of the participants indicated that they were service connected for physical disability.

Table 1

Demographic Characteristics of the Sample

\begin{tabular}{lcc}
\hline Characteristic & $N$ & $\%$ \\
\hline Sex & & \\
Male & 94 & 71.8 \\
Female & 37 & 28.2 \\
\hline
\end{tabular}


Table 1 (continued).

\section{Race/Ethnicity}

White, Non-Hispanic

97

74.0

Black, African American

20

15.3

Hispanic

5

3.8

Asian/Pacific-Islander

3

2.3

American Indian/Alaskan Native

2

1.5

Other

4

3.1

Service Branch

Air Force

34

25.9

Army

55

42.0

Coast Guard

3

2.3

Marine Corps

24

18.3

Navy

17

13.0

Marital Status

Single

45

34.4

Married

66

50.4

Separated

4

3.1

Divorced

16

12.2

Time since last deployment

Less than 6 months

2

1.5

6 months to 1 year

5

3.8 
Table 1 (continued).

1 year to 2 years

More than 2 years
8

114
6.1

87

\section{Measures}

\section{Demographic Questionnaire}

Participants completed a general demographic questionnaire to assess personal and military-related background information. Such information included gender, age, marital status, education level, race/ethnicity, duration and location of deployment, current military status (i.e. active, reserve, separated, or retired), branch of military service, current employment status, and hours of work per week if employed.

\section{Posttraumatic Stress}

The Posttraumatic Stress Disorder Checklist-Military Version (PCL-M; Weathers, Litz, Herman, Huska, \& Keane, 1993) is a 17-item self-report measure of PTSD symptoms. PCL-M items were written using criteria for posttraumatic stress disorder according to DSM-IV-TR criteria (Cook, Elhai, Cassidy, Ruzek, Ram, \& Sheikh, 2005). Respondents are asked to rate how often they are affected by different symptoms on a five-point Likert scale with items such as "being super alert or watchful on guard" and "feeling jumpy or easily startled" with responses ranging from Not at all (1) to Extremely (5). Higher scores indicate greater severity or more prevalent PTSS for the individual. Total scores may range from 17 to 85 , with a total score of 50 or higher indicating that a diagnosis of PTSD is warranted (Hoge, Castro, Messer, McGurk, Cotting, \& Koffman, 2004). The total score was used for analysis in the present study. Items on the PCL-M 
represent the three clusters outlined in the DSM-IV-TR as criteria for a diagnosis of PTSD (Cook et al, 2005.). These include re-experiencing symptoms (cluster B), avoidance/numbing symptoms (cluster C), and hyperarousal symptoms (cluster D).

The PCL-M has been employed to evaluate PTSD symptoms in veterans returning from the wars in Iraq and Afghanistan (Erbes et al., 2007). Adequate test- retest reliability of the PCL-M has been reported by Weathers et al. (1993) to be .96 over a 2-3 day interval. Keen, Kutter, Niles, and Krinsley (2008) reported adequate internal consistency $(\alpha=.94)$ for total scores and for individual symptoms clusters as measured by the PCL-M ( $\alpha=.91-.96)$. Convergent validity was established between the PCL-M and the Clinician-Administered PTSD Scale with significant correlations found to range from .79 to .93 (Blanchard \& Jones-Alexander, 1996; Keen et al., 2008). For the current sample, Cronbach's alpha was .95.

\section{Sense of Coherence}

The Sense of Coherence Scale-13 (SOCS-13; Antonovsky, 1993) is a 13-item self-report measure used to assess sense of coherence as defined by Antonovsky (1987). This measure is a shortened form of Antonovsky's original 29-item measure of this construct. The three components assessed are an individual's belief that one's life is manageable, meaningful, and comprehensible (Antonovsky, 1987). Respondents are asked to rate how well statements apply to various aspects of their life on a 7-point Likert scale. Wording of item responses differ for each statement with items such as "how often do you have feelings that you are not sure you can control" and "do you have the feeling that you really don't about what is going on around you" with two opposite anchoring phrases on each end (1) being "never" and (7) being "always." Five items are reversed 
scored and total scores range from 13 to 91 with higher scores indicating stronger SOC. The total score was used in analyses of research questions.

The SOC-13 has demonstrated adequate internal consistency across a range of investigations ( $\alpha=.74-.91$; Antonovsky, 1993; Feldt et al., 2003; Klepp, Maskekaasa, Sorenson, Sandanger, \& Kleiner, 2007). Comparisons between clinical and non-clinical populations indicated significant differences with higher levels of SOC in non-clinical populations (Frenz, Carey, \& Jorgenson, 1993). Confirmatory factor analysis has provided support for the hypothesized three factor structure of this measure as a superior model compared to a unidimensional structure (Feldt et al., 2003). However, the high correlations between factors and high factor loadings on the second-order factor for comprehensibility and manageability constructs indicate that for empirical research, total scores should be utilized (Feldt et al., 2003). This is echoed in Klepp et al. (2007) with confirmatory factor analysis indicating that the subscales are more likely facets of a global factor rather than separate factors. Therefore, the current study used only a total score as measurement of the global construct of sense of coherence in subsequent analysis. The scale demonstrated construct validity, as significant inverse relationships were found between SOC and perceived stress, trait anxiety, and depression (Frenz et al., 1993). For the current sample, Cronbach's alpha was .89 .

\section{Vocational Identity}

My Vocational Situation (MVS: Holland, Daiger, \& Power, 1980) is a 26-item self-report measure that was created as a diagnostic and career planning tool. For the current study, the 18-item subscale of Vocational Identity (MVS-VI) was utilized. This subscale measures the extent to which an individual possesses a clear and stable 
understanding of one's own career goals, interests, personality, and talents (Holland, Daiger, \& Power, 1980; Strauser et al., 2008). Respondents are asked to indicate whether items such as “I don't know what my major strengths and weaknesses are” and "I'm not sure that my present occupational choice or job is right form" apply to their vocational experiences through True or False responses. The number of False responses increases scores on this subscale and indicates a stronger vocational identity.

The MVS-VI has demonstrated adequate internal consistency with Alpha coefficients reported to range from .86-.89 (Holland, Daiger, \& Power, 1980; Strauser et al., 2006; Strauser et al., 2008). Construct validity has been established in comparison to other mental health and career-related variables. Strong positive correlations have been established between the MVS-VI and career self-efficacy and career decision-making self-efficacy (Strauser et al., 2006). Significant negative correlations have been found between the MVS-VI and trauma symptoms and barriers to information (Strauser et al., 2006). For the current sample, Cronbach's alpha was .89.

\section{Work Role Functioning}

The Social Adjustment Scale-Self Report (SAS-SR: Weismann, 1999) is a 54item self-report measure that assesses an individual's ability to adapt to and derive satisfaction from different social roles (Weismann, 1999). This study utilized the subscale meant to assess work role functioning and adjustment. This subscale is a measure of overall work role functioning, including performance, attendance, and confidence in both work and school over the past two weeks (Erbes et al., 2011). Work roles are differentiated on this measure so that functioning may be assess for a person working without pay (i.e. students, homemakers; Weissman, Olfson, Gameroff, Feder, \& 
Fuentes, 2001). Respondents are asked questions such as "how often have you been ashamed of how you did your work in the last 2 weeks" and "how many days did you miss from work in the past 2 weeks," and response options are provided on a five-point Likert-type scale with higher scores indicating poorer role functioning (Allison, 2003; Weissman et al., 2001). Adequate internal consistency has been reported by Weissman (1999) with Alpha coefficients ranging from .71 to .76. Acceptable test-retest reliability has been established over a two-month interval with correlations ranging from .72-.82 (Allison, 2003). For the current sample, reliability was calculated for this measure, and Cronbach's alpha was .87 indicating strong internal consistency.

Procedure

The University of Southern Mississippi’s Institutional Review Board approved the current study (see Appendix B). The study measures were disseminated through Qualtrics, a secure online service provider (usmep.qualtrics.com). Privacy was ensured so that data were accessible for the researcher with a secure password. Participants were recruited via social networking, including Facebook and Twitter, email contacts for veteran service organizations and Student Veterans of America chapter representatives across the country, as well as personal email contacts. A link was included in all email communications, and fixed links were available on Facebook and Twitter pages dedicated to this study and created by the researcher. The researcher attempted recruitment through Amazon's Mechanical Turk but this did not yield any participants for the current study.

Upon clicking the survey link, participants were directed to an informed consent document. Following agreement to participate, respondents completed a demographic information form. Participants were then presented with the following measures in 
random order, determined by the online survey system: the PCL-M, SOC-13, and MVSVI. Following completion of these measures, participants then completed the SAS-SR before being prompted to assign a donation to be made in their honor to a choice of three veteran service organizations (i.e., Wounded Warrior Project, Student Veterans of America, Iraq and Afghanistan Veterans of America). The SAS-SR was not included in randomization of measures due to restrictions of the published measure. The researcher purchased 150 administrations of this measure and to ensure that this number was not exceeded by individuals that did not complete the entire survey, the measure was completed last by all participants to protect from early termination. Two validity items were placed throughout the survey (one in the MVS-VI and one in the SOC-13) which instructed participants to select a particular response as suggested by Meade and Craig (2012) as a strategy to guard against random responding in the sample. 


\section{CHAPTER III - RESULTS}

Missing data for the sample were replaced using linear trend at point procedure. Eight data points were replaced across eight items completed by three participants retained in the analysis sample using this method. Descriptive statistics for study measures' total scores are presented in Table 2 along with means, standard deviations, and correlations for study measures. Significant relationships between initial enlistment as a reservist versus active duty have previously been found to be significantly associated with symptoms of PTSD (Milliken et al., 2007). Thus, bivariate correlations between this demographic variable and PCL-M scores were evaluated and found to be not significant $(r=.103, p=.24)$. Bivariate correlations between additional demographic variables including gender, marital status, and race/ethnicity were also evaluated for all measures and found to be not significant. Inspection of Malahanobis distance values was conducted to test for the presence of multivariate outliers in the sample. All cases did not exceed critical values, thus all 131 participants were retained in analyses.

Table 2

Means, Standard Deviations, and Correlations

\begin{tabular}{|c|c|c|c|c|}
\hline Study Measure & PTSS & $\mathrm{SOC}$ & VI & WRF \\
\hline 1. PTSS & -- & & & \\
\hline 2. SOC & $-.79 * *$ & -- & & \\
\hline 3. VI & $-.43 * *$ & $.61 * *$ & -- & \\
\hline 4. WRF & $.64 * *$ & $-.68 * *$ & $-.42 * *$ & -- \\
\hline M & 39.92 & 57.96 & 29.11 & 1.74 \\
\hline
\end{tabular}


Table 2 (continued).

\begin{tabular}{lcccc}
\hline SD & 16.59 & 15.61 & 5.14 & 0.52 \\
Range & $17-77$ & $23-89$ & $18-36$ & $1-3.33$ \\
Possible Range & $17-85$ & $13-91$ & $18-36$ & $1-5$ \\
Sample Alphas & .95 & .89 & .89 & .87 \\
\hline
\end{tabular}

Note. PTSS=posttraumatic stress symptoms; SOC=sense of coherence; VI=vocational identity; WRF=work role functioning.

\section{Research Question 1}

Path analysis was utilized to test the first research question which investigated influences on work role functioning and hypothesized that sense of coherence, posttraumatic stress symptoms, and vocational identity would significantly predict work role functioning, with posttraumatic stress predicting vocational identity, thus having an indirect effect on work role functioning. Hypothesis 1a predicted that PTSS would predict work role functioning. Analysis of the data indicate that this is a significant relationship $(\beta=.309, p<.001)$. Hypothesis $1 \mathrm{~b}$ stated that stronger sense of coherence would predict more effective work role functioning. This relationship was found to be significant $(\beta=-.502, p<.001)$ and in the expected direction due to the previously noted scoring of associated measures (i.e. low scores on work role functioning measure indicates optimal functioning and high scores on sense of coherence measures indicate stronger sense of coherence). The third hypothesis predicted that more stable vocational identity would predict more effective work role functioning. This hypothesis was not supported $(\beta=-.035, p=.649)$. The final hypothesis for the first research question predicted that PTSS would significantly predict vocational identity which was found to be the case $(\beta=-.430, p<.001)$. Further, this final hypothesis stated that posttraumatic 
stress would have an indirect effect on work role functioning which was found to be significant. To test indirect effects, a bootstrapping method (Hayes, 2009) was utilized in which the data collected were resampled 5000 times to calculate estimates for the paths from PTSS to vocational identity and the path from the vocational identity to the outcome variable (work role functioning). This resampling technique then produces a $95 \%$ confidence interval containing these estimates, and if zero is not contained within this interval, it is inferred that the proposed mediator serves such a role in the proposed model. This indirect effect was not significant at the $95 \%$ confidence interval due to this range, including zero $(\beta=-.016$ and $\beta=.011)$, indicating that posttraumatic stress symptoms do not have an indirect effect on work role functioning through vocational identity. Results of the proposed model and associated path analysis are presented in Figure 1, consistent with reported relationships.

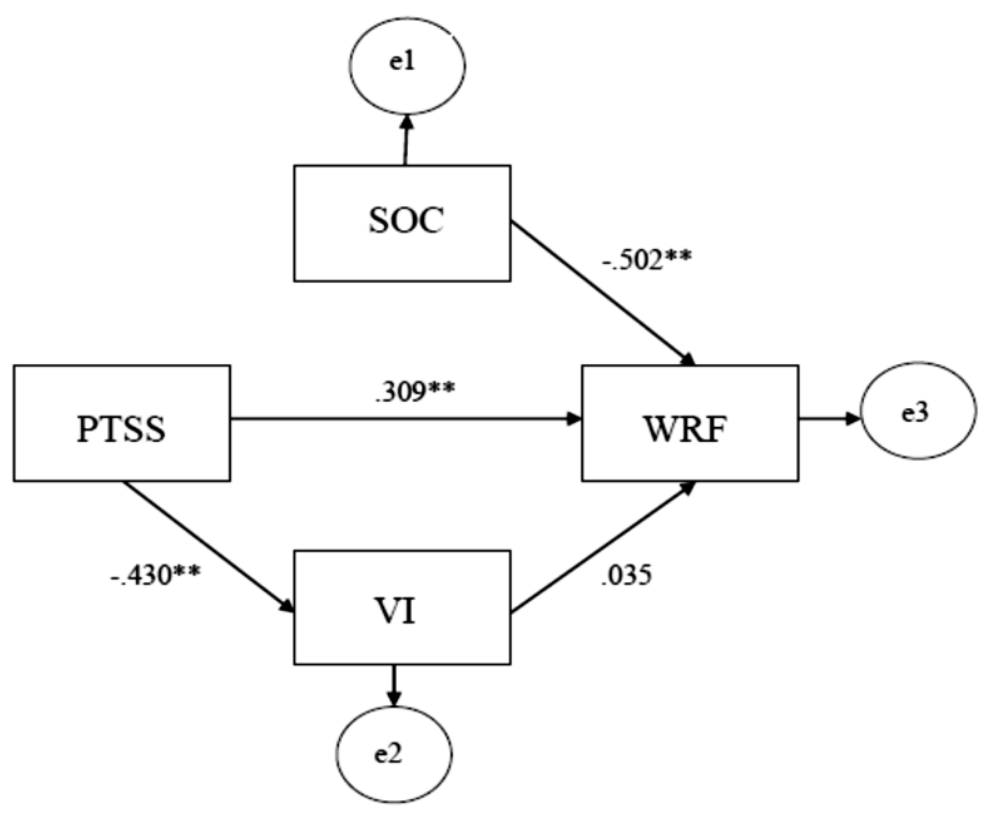

Figure 1. Research Question 1 Pathways.

PTSS = posttraumatic stress symptoms; $\mathrm{SOC}=$ sense of coherence; $\mathrm{VI}=$ vocational identity; WRF $=$ work role functioning. $* * p<.01$. 


\section{Research Question 2}

Path analysis was utilized to test the second research question which further investigated influences on work role functioning and hypothesized that sense of coherence would serve as a partial mediator in the relationship between PTSS and workrole functioning. The first step in testing for partial mediation was to establish that a significant prediction relationship exists between the predictor (PTSS) and the proposed mediator (SOC). This was established as a significant relationship $(\beta=-.852, p<.001)$. Further, a significant relationship was established between the mediator (SOC) and the dependent variable (work role functioning) in the first research question. When the variable of sense of coherence was added as a mediator in the model, the relationship that was established as significant in the first research question between the predictor (PTSS) and the dependent variable (work role functioning) was no longer significant $(\beta=.280$, $p=.104)$. This change in the relationship between the predictor and outcome variable after the addition of the proposed mediator supports the hypothesis. To further confirm partial mediation, bootstrapping methods as described previously were used and data was resampled 5,000 times, producing a 95\% confidence interval. Results showed a significant total indirect effect $(\beta=.011)$ of the predictor on the dependent variable, with zero not being contained in the $95 \%$ confidence interval of $\beta=.007$ to $\beta=.015, p=<.05$. These results indicate that sense of coherence serves as a mediator in the relationship between posttraumatic stress symptoms and work role functioning in the current sample. Further evaluation of the effect on the relationship between posttraumatic stress symptoms and work role functioning was conducted to determine if this mediation was partial or full in nature. Thus, the magnitude of reduction in the strength of the 
relationship between PTSS and work role functioning was calculated and differences in significance values were assessed. In the current study there was a $43.7 \%$ reduction in the relationship between PTSS and work role functioning $\left(\beta_{1}=.641, \beta_{2}=.280\right)$ and changes in $p$ value from $p<.001$ to $p=.104$. While some experts suggest an $80 \%$ reduction in the initial relationship to constitute full mediation (Baron \& Kenny, 1986), the magnitude of change in the relationship and meaningful change in significance suggests that senses of coherence fully mediates the relationship between PTSS and work role functioning. Results of the tested model are presented in Figure 2.

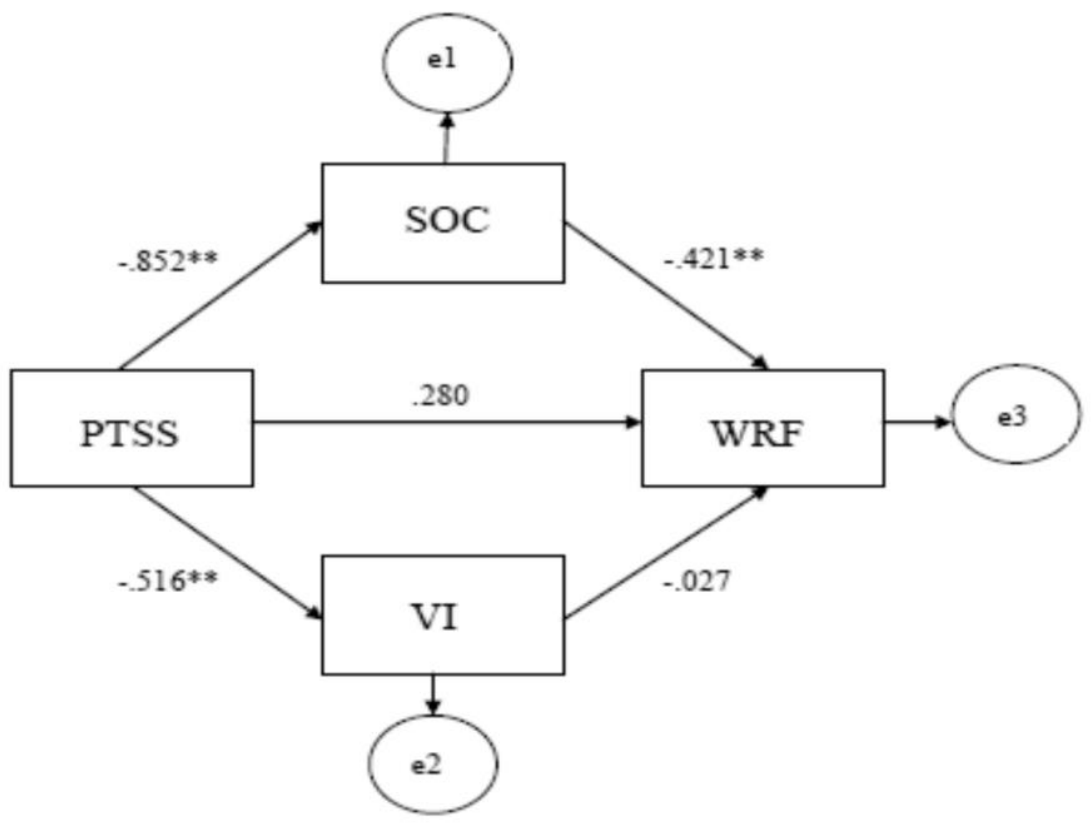

Figure 2. Research Question 2 Pathways

PTSS $=$ posttraumatic stress symptoms; $\mathrm{SOC}=$ sense of coherence; $\mathrm{VI}=$ vocational identity; $\mathrm{WRF}=$ work role functioning. $* * p<.01$ Research Question 3

To determine whether assumptions of normality, linearity, and homoscedasticity were met, a series of visual review and statistical analyses were utilized. Visual inspection of distributions, linearity, and variance of residuals suggested that assumptions 
were met. Further, collinearity statistics were within acceptable ranges (tolerance values ranged from .362 to .914 , variance inflation factors ranged from 1.09 to 2.76 , and condition indices ranged from 1.00 to 3.09). Thus, it appears that the assumptions of regression were not violated in this sample.

Hierarchical multiple regression was utilized to assess the third hypothesis, that sense of coherence will not function as a moderator in the relationship between PTSS and work role functioning. As no demographic variables were found to significantly correlate with the variables, none were entered into the model. The first block of the regression analysis contained the independent variable (PTSS) and the proposed moderator (SOC). Further, as results of the first research question illustrated that vocational identity did not exhibit significant effects on work role functioning, this variable was also excluded from this analysis. The second block of the regression contained the interaction term for the independent variable (PTSS) and the moderator (SOC). Scores on the PCL-M and the SOC-13 were centered prior to creation of the interaction term. The first model accounted for $49.3 \%$ of the variance in work role functioning. After additional accounting for the interaction term, the total model accounted for $50.4 \%$ of the variance in work role functioning. The second step was not significant $(\Delta R 2=.011, p=.090)$, indicating that the effects of PTSS on work role functioning does not vary as a function of reported sense of coherence. Results of this analysis are presented in Table 3. 
Table 3

Summary of Regression for Work Role Functioning

\begin{tabular}{lccc}
\hline \multicolumn{1}{c}{ Variable } & $\mathrm{B}$ & $R^{2}$ & \\
\hline Step 1 (Main Effects) & & $.485^{* *}$ & \\
PTSS & -.468 & & \\
SOC & .271 & & $\Delta R^{2}$ \\
\hline & $\mathrm{B}$ & $R^{2}$ & \\
\hline Step 2 (Interaction) & & & $.011^{n s}$ \\
PTSS x SOC & -.112 & $.493^{n s}$ & \\
\hline
\end{tabular}

Note. PTSS=posttraumatic stress symptoms; SOC=sense of coherence; WRF=work role functioning. Beta-weights reported for main effects. Standardized regression coefficient reported for the interaction. $* * \mathrm{p}<.01 ; \mathrm{ns}=$ not significant.

Research Question 4

Hierarchical multiple regression was utilized to assess the fourth hypothesis, that sense of coherence will function as a moderator in the relationship between PTSS and vocational identity reported by participants. As with the third research question, the first block contained only the independent variable (PTSS) and the proposed moderator (SOC). The second block of the regression contained the interaction term for the independent variable (PTSS) and the moderator (SOC). Scores on the PCL-M and the SOC-13 were centered prior to creation of the interaction term. The first model accounted for $37.3 \%$ of the variance in vocational identity. After additional accounting for the interaction term, the total model accounted for $37.4 \%$ of the variance in vocational identity. The second step was not significant $(\Delta R 2=.001, p=.668)$, indicating that the 
effects of PTSS on vocational identity do not vary as a function of reported sense of coherence. Results of this analysis are presented in Table 4.

Table 4

Summary of Regression for Vocational Identity

\begin{tabular}{lccc}
\hline \multicolumn{1}{c}{ Variable } & B & $R^{2}$ & \\
\hline Step 1 (Main Effects) & & $.373^{* *}$ & \\
PTSS & .707 & & \\
SOC & .271 & & $\Delta R^{2}$ \\
\hline & $\mathrm{B}$ & $R^{2}$ & \\
\hline Step 2 (Interaction) & & & $.001^{n s}$ \\
PTSS x SOC & .032 & $.374^{n s}$ & \\
\hline
\end{tabular}

Note. PTSS=posttraumatic stress symptoms; $\mathrm{SOC}=$ sense of coherence; WRF=work role functioning. Beta-weights reported for main effects. Standardized regression coefficient reported for the interaction. $* * \mathrm{p}<.01 ; \mathrm{ns}=$ not significant. 


\section{CHAPTER IV - DISCUSSION}

The current study sought to examine the relationship between mental health concerns of OEF and OIF veterans and work role functioning. Specifically, this study explored relationships between PTSS and effective functioning in various work roles and possible influential variables such as sense of coherence and vocational identity. Past research has called for more attention to relationships between the mental health of veterans and potential buffering effects to improve employment outcomes and performance in civilian work roles (Zivin et al., 2012). Recent research has brought to light the impact that PTSS can have on functionality in social, personal, and occupational arenas, especially with our most recent combat era veterans (Breslau, Lucia, \& Davis, 2004; Hourani et al., 2012; Pietrzak, Goldstein, Malley, Rivers, Morgan, \& Southwick, 2010; Rona et al., 2009; Stein, McQuaid, Pedrelli, Lenox, \& McCahill, 2000).

In this investigation, various methods were used to assess factors that may help to improve functioning in veteran's varying civilian work roles. Specifically, the influence of sense of coherence was examined through path analysis and hierarchical multiple regression to better understand how practitioners may promote optimal functioning among veterans separating from military careers. Past research studying resilience among individuals that have been exposed to traumatic events has indicated a correlation between the components of sense of coherence and constructs of resilience (Almedom, 2005; Antonovsky, 1987; Kroninger-Jungaberle \& Grevenstein, 2013). The current study furthers previous work that has found associations between sense of coherence and improved work-related functioning in civilian samples (Strauser \& Lustig, 2003). Additionally, previous research suggests that reports of more stable vocational identify 
have been associated with less negative career thinking and better psychological wellbeing (Strauser et al., 2008). This study sought to add to literature that is just beginning to understand the link between trauma and vocational identity.

The construction of the model used in answering the first research question focused on the overall relationships that were proposed to contribute to work role functioning among U.S. veterans. That is, to examine the predictive nature of posttraumatic symptoms in relation to work role functioning and how individuals' reports of comprehensibility, meaningfulness, sense of manageability, and stability of their identity in work influenced this relationship. Hypotheses for the first research question predicted that PTSS and sense of coherence would predict work role functioning and that vocational identity would also be a significant predictor of this outcome. Further, it was hypothesized that PTSS would also predict vocational identity among this sample. In line with expectations, PTSS and sense of coherence significantly predicted work role functioning. In the sample, reports of fewer PTSS predicted better work-role functioning behaviors and attitudes and vocational identity, in line with hypotheses. Further, vocational identity was not a significant predictor of work role functioning, and an indirect path through vocational identity was not found in the relationship between PTSS and work-role functioning

The model suggested by the second research question postulated that sense of coherence would partially mediate the relationship between PTSS and work-role functioning in the sample. This hypothesis was supported by the current study. The two final research questions sought to investigate possible moderating roles of sense of coherence in the proposed relationships. Results suggest that sense of coherence did not 
serve as a moderator in the relationship between PTSS and work role functioning, nor in the relationship between PTSS and vocational identity.

Results of the current study expand the literature base through investigation of the impact of posttraumatic stress of veterans in relation to work role functioning. Specifically, the expansion of traditional definitions of "work roles" went beyond paid work in this investigation and included enrollment in school as well as taking care of the home as qualified "work." Instead of classifying these roles as social or family roles as previous research has (Breslau, et al., 2004; Hourani, et al., 2012; Pietrzak, Goldstein, et al., 2010), the current study addressed these in the context of work, leaving participants to identify which role they personally define as the primary role. As more veterans are taking advantage of benefits following disconnection from service in the OEF/OIF/OND era, utilizing a broader definition of work may help researchers and practitioners to gain a more accurate picture of transitional functioning for veterans.

Though work role functioning was found to be significantly correlated with all other variables in the study, it is important to note that participants appeared to be wellfunctioning individuals. Specifically, with a range of possible scores being 1-5 and a mean of 1.74 (lower scores indicating better functioning), these individuals overall were not reporting behaviors or attitudes consistent with current problems effectively functioning in their identified work roles. Conversely, the reported level of stability of vocational identity among participants was more variable, which may suggest that vocational identity may not impact individuals' ability to actually perform their work roles in context of their reported PTSS. The lack of significant results found in investigating the mediating and moderating role of this variable support this possibility. 
However, the significant correlations and predictive relationship found between posttraumatic symptoms and vocational identity do add to previous research that has established links between these variables among undergraduates (Strauser et al., 2006).

Additionally, the majority of participants (66.4\%) endorsed engaging in more than one work role over the past two weeks when completing the survey. Nearly three quarters $(74 \%)$ of the sample were enrolled in school when this survey was distributed. When considering the vocational identity as a measure of stability of one's view of themselves in context of goals and interests, for veterans, this may not be as applicable. Veterans may experience a different path of career development that does not lend itself to significant impact of vocational identity on their ability to function at work. The length of service prior to discharge from the military was not assessed in the current study, but $87 \%$ had been separated for two or more years. For those individuals that anticipated the military as a career, vocational identity may still be linked to military work roles and not influencing functioning in new work roles such as housework or as a student.

Further, the level of service connection for these veterans is unknown and for those with a significant amount of income being received, their stability of vocational identity may be influenced. If individuals have obtained non-employable status by the Veterans Benefits Administration (VBA), then unemployability may be their vocational identity and not impact their ability to complete tasks such as housework. While symptoms of posttraumatic stress were significantly correlated with vocational identity in the current sample, it does not appear that beliefs consistent with sense of coherence impact the relationship between trauma symptoms and vocational identity in the current 
sample. This relationship may better be explained by the influence of other variables, or that the relationship goes in a different direction such as mental health concerns playing more of a role in the relationship between sense of coherence and vocational identity.

As a primary aim of this study was to evaluate the role of sense of coherence in the relationships of PTSS with work role functioning and vocational identity, results around this construct are of particular interest. Correlational results found here among PTSS and sense of coherence are in line with prior research that has established negative relationships with sense of coherence and other variables of psychopathology such as depression and anxiety (Kroninger-Jungaberle \& Grevenstein, 2013). Additionally, expected correlations between work role functioning and sense of coherence are in line with prior research finding that sense of coherence may promote engagement in adaptive work behaviors such as performing tasks independently in civilian populations (Strauser \& Lustig, 2003). This study adds to this line of research by including attitudes and beliefs about one's functioning at work and not only behavioral aspects of performance in a veteran population.

Further, as hypothesized, sense of coherence served as a mediator and not a moderator in the relationship between posttraumatic stress and work-role functioning. The affirmative mediation results are in line with previous research that has established sense of coherence as a variable that helps to explain the relationship that many have found between other mental health concerns, such as anxiety, and outcomes of satisfaction with life (Gana, 2001) as well as traumatic stress or exposure to trauma and overall well-being (Ferrajao \& Oliveira, 2016; Veronese \& Alessandro, 2014; Zeidner \& Aharoni-David, 2015). 


\section{Clinical Implications}

The purpose of this study overall was to evaluate variables that impact work role functioning in effort to inform mental health treatment of OEF/OIF veterans of the U.S. military and help to promote effective functioning in civilian work roles. Results indicate that sense of coherence likely serves as factor that can impact functioning in the context of PTSS. It is proposed that clinical interventions aimed at strengthening veterans' sense of coherence would improve functioning in work roles. The lack of significant moderation of the relationship between symptoms and functioning by sense of coherence suggests that weak sense of coherence is not necessarily a risk factor for poorer work functioning. However, its mediation of this relationship indicates it would likely be helpful to augment interventions to target sense of coherence in effort to improve functioning in work roles among veteran's experiencing PTSS. Ferrajao and Oliveira (2016) have suggested that developing stronger sense of coherence plays a major role in recovery from symptoms of posttraumatic stress and the current study further supports this assertion. Specifically, in relation to vocational rehabilitation programs or efforts to improve veterans' ability to effectively engage in work related activities, strengthening sense of coherence through clinical interventions may serve this effort.

Though this may be the case, the ability of interventions to directly affect sense of coherence has been scarcely researched. In one study of whether it is even possible to improve sense of coherence through group interventions, Kahonen, Naatanen, Tolvanen, and Samela-Aro (2012) found that it in short group interventions among employees suffering from burnout symptoms, it is possible to enhance this variable. Other research has found integration of the salutogenic theory behind sense of coherence may be helpful 
in treating patients with Obsessive-Compulsive Disorder in conjunction with medication (Joachim, Lyon, \& Farrell, 2003). Further, group therapy based on salutogenic principles have been found to improve sense of coherence among participants with mental health concerns, particularly related to their belief that they can manage stressors in their world (Langeland et al., 2006).

Vossler's (2012) research related to sense of coherence and the role of salutogenesis in therapy suggests that it is possible to facilitate strengthening of sense of coherence in counseling and psychotherapy. Specifically, it is suggested that utilization of third wave cognitive behavioral approaches to psychotherapy such as Acceptance and Commitment Therapy (ACT) or mindfulness-based therapies may serve to enhance sense of coherence as these approaches encourage exploration of inner and outer experiences including concepts associated with comprehensibility and manageability (Vossler, 2012). However, measures of sense of coherence are very seldom used in measuring outcomes of therapeutic interventions, particularly in research (Vossler, 2012). It is suggested that in light of the current research suggesting that sense of coherence plays a significant role in functioning in work roles, especially in relation to PTSS, that researchers and practitioners alike may be served by including interventions aimed at improving sense of coherence and actively measuring changes in this variable throughout therapy to address functioning.

Within Veterans Affairs (VA) treatment facilities, there has been a major policy shift in the treatment of mental health toward therapies that are considered evidence based therapies (EBT: Steenhamp, Litz, Hoge, \& Marmar, 2015). Currently there are thirty-five specialized PTSD units in the United States VA healthcare system (Desai, 
Spencer, Gray, \& Pilver, 2009) and EBTs provided for PTSD generally include cognitive processing therapy (CPT), prolonged exposure (PE), eye movement desensitization and reprocessing therapy (EMDR), and other interventions based on stress management or inoculation (Steenkamp, Litz, Hoge, \& Marmar, 2015). Randomized clinical trials have followed this shift to evaluate how well treatments have fared in reducing symptomology among veteran and civilian populations with several meta-analyses suggesting that CPT and PE studies show greater effect sizes than all other treatments implemented that have been included in these analyses (Haagen, Smid, Knipscheer, \& Kleber, 2015; Steenkamp et al., 2015).

Even with the increased focus on EBTs, consistently research is suggesting that therapy provides limited symptom reduction in the veteran population when compared to civilians with PTSD diagnoses (Haagen et al., 2015). Steenkamp and colleagues (2015) note that the focus of current $\mathrm{CPT}$ and PE are the beliefs surrounding trauma and specifically, beliefs about one's ability to survive distressing events and create realistic, manageable, and helpful thoughts about adapting to trauma. Further, they highlight a need for improvement in these current therapeutic PTSD treatments and suggest that developing novel EBT strategies is necessary to move PTSD treatment forward (Steenkamp et al., 2015). Research has found work adjustment to aid in creating successful transitions for civilians (Strauser \& Lustig, 2003), and the current study may help steer clinicians toward a possible avenue toward building more sustainable treatment programs. Thus, incorporation of additional treatment modalities, which may strengthen sense of coherence, with established EBTs may prove to enhance current veteran response to treatment as functioning in work roles may lend to enriched recovery from 
PTSD. These interventions may be implemented in both VA settings as well as colleges and universities. Within the current sample, $74 \%$ of participants reported attending school and may be receiving services for mental health concerns through student counseling services. These settings may just as easily apply strategies of EBTs and augmentations to address sense of coherence when goals include improving functioning at work or at school in the context of posttraumatic stress symptoms.

Vocational rehabilitation, ACT, or mindfulness based therapies may be helpful additions as suggested by Vossler (2012) in civilian populations. Preliminarily, research has found some benefit for veterans suffering from PTSD that undergo mindfulness based therapy and ACT interventions (Dimijdian \& Segal, 2015; Woidneck, Morrison, \& Twohig, 2014). In primary care, veterans have shown decrease in PTSD symptom severity following brief mindfulness based treatment (Possemato, Bergen-Cico, Treatman, Allen, Wade, \& Pigeon, 2016). Mindfulness based interventions have also been to improve overall quality of life among veterans with PTSD (Marzabadi \& Hashem Zadeh, 2014), but there is mixed evidence of the sustainability of relief from PTSD symptoms (Niles, Klunk-Gillis, Ryngala, Silberbogen, Paysnick, \& Wolf, 2012). The addition of strategies aimed at improving sense of coherence may serve to aid in creating long term relief with mindfulness based treatments as work role functioning may in turn be improved. Further, the simple addition of measures of sense of coherence to outcome research may be helpful to determine if current EBPs are already providing support for strengthening sense of coherence and/or if this change may be sustainable.

Additionally, in consideration of the components of sense of coherence's manageability facet, simply providing resources to veterans may aid in improving 
functioning. Veterans' awareness of resources through the VA, colleges, or service organizations may aid in improving perceptions that the veteran has the resources to manage stressful life events. Many universities have already integrated such strategies such as providing student veterans with the knowledge of where they can find staff and counseling services that are trained to help them with veteran-specific transition issues.

\section{Limitations and Future Research}

Consideration of limitations in the present study is recommended when reviewing the results gleaned from analysis and looking toward future research directions. A main limitation of the current study is recruitment procedures. Participants in the current study were recruited from a community setting and because of this, and a desire to maximize participation, many unknown variables were not assessed such as mental health treatment and diagnoses (current or historical). Though approximately $25 \%$ of the sample indicated service connection for mental health diagnoses, this does not necessarily indicate that they have received treatment for these concerns. Further, participants may carry a mental health diagnosis, including PTSD, depression, and substance use disorders and not be service connected, but receiving treatment. It is possible that participants may have engaged in treatment in the past and this contact, or a lack of contact, may influence their current reports of PTSS, current functioning, and beliefs in line with principles of sense of coherence or vocational identity. Recruitment procedures were also limited to social media and personal contacts of the researcher. This may serve to explain the limitation of the sample appearing relatively well functioning.

Relatively stable vocational identities and adaptive functioning in work roles reported were reported in the current sample and it is possible that this may indicate a 
selection bias for participation. Participants may have opted to participate due to feeling secure and well-functioning or connection to the researcher. Additionally, level of service connection was not assessed in the current sample. This information may be helpful in better understanding veterans' vocational identity in light of the level of financial support from the military they continue to receive. If veterans are completely service, connected and currently considered unemployable, their vocational identity may not be impacting ability to complete household tasks. Future research should assess possible differences in vocational identity and functioning in the context of level of service connection. Future research should also consider replication of these procedures with a more diverse sample of veterans, including those that are currently seeking treatment for mental health concerns, whether it is for PTSD or other disorders characteristic of the OEF/OIF population. It is likely that individuals seeking treatment will have more impairment in work functioning and therefore provide stronger support for the relationships presented here, if found.

Caution should be taken in generalizing the current results to these individuals given the relatively low PTSS reporting and overall adaptive functioning in work roles. The present study assessed only work roles and other areas may or may not indicate the same relationships with sense of coherence and posttraumatic stress. It is still unknown if sense of coherence would affect the relationships with other areas of functioning (i.e. social, family). This study further only assessed one area of identity development, vocational identity, and found that although PTSS does significantly predict this identity, other aspects of this relationship where not assessed. Specifically, other variables, both related to posttraumatic stress and not, may be significantly involved in stability of 
vocational identity. These should be further assessed and as in the case of functioning in work roles, having a more diverse sample of symptomology may help to shed light on the complexities of vocational identity among veterans. Sex differences were not assessed in relation to the proposed model and future research may benefit from investigating the role of this demographic variable and others. Evaluation of demographic influences may serve to identify who would benefit from clinical interventions discussed here. Further, preliminary analysis suggested that this sample did not exhibit significant differences of variables according to sex. Future research however may be served by investigation of sex influences on the model tested here due to possible work role differences.

Additionally, a limitation of this study is the focus on only work role functioning as a measure of adaptation following military service. In utilizing a salutogenic model of treatment and mental health, assessment of other areas such as posttraumatic growth should be assessed within the current model in the future. Assessment of how posttraumatic growth, or positive psychological change (Tedeschi \& Calhoun, 2004), may impact functioning of veterans as well and its relationship with sense of coherence. Posttraumatic growth as a positive marker of recovery is beginning to garner more research attention and examining its relationship to overall functioning and aspects of sense of coherence would further add to literature of recovery-oriented treatment of PTSD.

\section{Conclusion}

The current study presented an opportunity to expand understanding of the complex relationship between symptoms of PTSD and functioning in civilian work roles among U.S. veterans. Results indicate that a strengthened sense of coherence may help 
buffer the effects of PTSS on work role functioning. This study expanded literature that has previously focused on social, emotional, and interpersonal functioning as well as expanding the definition of work in effort to gain a more holistic understanding of the proposed relationships. Vocational identity was also found to be significantly correlated with work role functioning; however it did not play a significant role in predicting functioning. In considering these results, it is suggested that future research explores strategies to aid in strengthening sense of coherence among veterans with PTSD in effort to improve functioning at work. Additionally, continued examination of the role that sense of coherence plays and outcomes of treatment that target this variable is suggested. The current study indicates the importance and necessity of improving functioning and treatment for our veterans in their transition from military to civilian roles following service. 


\section{APPENDIX A - Demographic Questionnaire}

1. Age

2. Gender

O Male

O Female

O Other

3. Racial/Ethnic Background

White or European American (Non-Hispanic)

O Black or African American (Non-Hispanic)

O Hispanic

O Asian/Pacific Islander

O American Indian/Alaskan Native

O Other

4. Are you currently employed?

$\mathrm{O}$ Yes

O No

Answer: If Are you currently employed? Yes Is Selected, then 5 displayed.

5. How often do you work?

O Less than 20 hours per week

O 20-40 hours per week

O 40 hours or more per week

6. Are you currently enrolled in school?

$\mathrm{O}$ Yes

O No

Answer: If Are you currently enrolled in school? Yes Is Selected, then 7 is displayed. 
7. What is your current classification in school?

O Freshman

Sophomore

O Junior

O Senior

Graduate Student

Answer: If Are you currently enrolled in school? Yes Is Selected, then 8 is displayed.

8. Are you receiving GI benefits for your education?

O Yes

No

9. Are you currently service connected for any mental health disorder?

O Yes

O No

Answer: If Are you currently service connected for any mental health disorder? Yes Is

Selected, then 11 is displayed

10. Are you currently service connected for Posttraumatic Stress Disorder?

O Yes

No

11. Are you currently service connected for any physical disability or injury?

O Yes

No 
12. Do you engage in any volunteer work or work NOT for pay?

$\mathrm{O}$ Yes

O No

13. In which branch of the United States Military did you serve?

O Air Force

O Army

Coast Guard

O Marine Corps

O Navy

14. Did you enlist as a reservist?

$\mathrm{O}$ Yes

O No

15. Please select all Operations/Wars that you took part in as a U.S. military service member.

Operation Iraqi Freedom/Operation Enduring Freedom

O Gulf War/Desert Storm

O Vietnam War

O Other

If Operation Iraqi Freedom/Ope... Is Not Selected, Then Skip To End of Survey

Answer If Please select all Operations/Wars that you took part in as a U.S. military service member. Operation Iraqi Freedom/Operation Enduring Freedom Is Selected, then 16 will display. 
16. Did you serve in BOTH Iraq AND Afghanistan?

O Yes

O No

17. How long has it been since you returned from your most recent deployment?

O less than 6 months

O 6 months to 1 year

O 1 year to 2 years

O More than 2 years

18. What is your current marital status?

O Single

O Married

O Separated

O Divorced

O Widow/ Widower 
APPENDIX B - Institutional Review Board Approval Letter

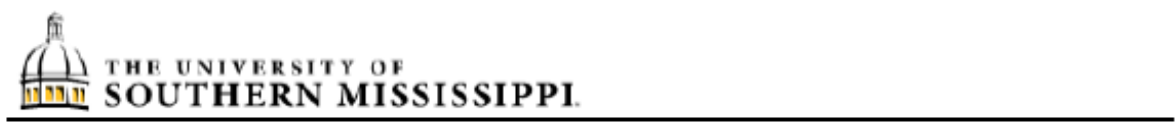

INSTIIUTIONAL REVIEW BOARD

118 College Drive \#5147 | Hattiesburg, MS 39406-0001

Phone: 601.266 .5997 | Fax: 601.266.4377 | www.usm.edu/research/institutional-review-board

NOTICE OF COMMITTEE ACTION

The project has been reviewed by The University of Southem Mississippi Institutional Review Board in accordance with Federal Drug Administration regulations (21 CFR 26, 111), Department of Health and Human Services (45 CFR Part 46), and university guidelines to ensure adherence to the following criteria:

- The risks to subjects are minimized

- The risks to subjects are reasonable in relation to the anticipated benefits.

- The selection of subjects is equitable.

- Informed consent is adequate and appropriately documented.

- Where appropriate, the research plan makes adequate provisions for monitoring the data collected to ensure the safety of the subjects.

- Where appropriate, there are adequate provisions to protect the privacy of subjects and to maintain the confidentiality of all data.

- Appropriate additional safeguards have been included to protect vulnerable subjects.

- Any unanticipated, serious, or continuing problems encountered regarding risks to subjects must be reported immediately, but not later than 10 days following the event. This should be reported to the IRB Office via the "Adverse Effect Report Form".

- If approved, the maximum period of approval is limited to twelve months.

Projects that exceed this period must submit an application for renewal or continuation.

PROTOCOL NUMBER: 14041401

PROJECT TITLE: Assessing US Veterans' Work-Role Functioning: Influences of

Posttraumatic Stress, Sense of Coherence, and Vocational Identity

PROJECT TYPE: New Project

RESEARCHER(S): Lauren Osborne, Ph.D.

COLLEGE/DIVISION: College of Education and Psychology

DEPARTMENT: Psychology (Counseling)

FUNDING AGENCYISPONSOR: N/A

IRB COMMITTEE ACTION: Expedited Review Approval

PERIOD OF APPROVAL: $04 / 15 / 2014$ to $04 / 14 / 2015$

Lawrence A. Hosman, Ph.D.

Institutional Review Board 


\section{REFERENCES}

Abma, F.I., Amick, B.C., van der Kling, J.J., \& Bultmann, U. (2013). Prognostic factors for successful work functioning in the general working population. Journal of Occupational Rehabilitation, 23, 162-169. doi: 10.1007/s10926-012-9410-0

Ainspan, N.D. (2011). From deployment to employment. U.S. Naval Institute Proceedings, 137(2), 44-49.

Albersten, K., Nielsen, M.L., \& Borg, V. (2001). The Danish psychosocial work environment and symptoms of stress: The main, mediating and moderating role of sense of coherence. Work and Stress, 15(3), 241-253. doi:

$10.1080 / 02678370110066562$

Allison, J.A. (2003). [Review of the Social Adjustment Scale-Self Report]. In B.S. Plake, J.C. Impara, \& R.A. Spies (Eds.), The fifteenth mental measurements yearbook. Lincoln, NE: Buros Institute of Mental Measurements.

Almedom, A.M. (2005). Resilience, hardiness, sense of coherence, and posttraumatic growth: All paths leading to "light at the end of the tunnel"? Journal of Loss and Trauma, 10, 253-265. doi: 10.1080/15325020590928216

American Psychiatric Association. (2013). Diagnostic and statistical manual of mental disorders (5th ed.). Washington, DC: American Psychiatric Association.

Antonovsky, A. (1987). Unraveling the mystery of health. San Francisco, CA: JosseyBass.

Antonovsky, A. (1993). The structure and properties of the Sense of Coherence Scale. Social Science and Medicine, 36, 725-733. 
Aspers, S., Luyckx, K., Rassart, J., Goossens, E., Budts, W., \& Moons, P. (2013). Sense of coherence is a predictor of perceived health in adolescents with congenital heart disease: A cross-lagged prospective study. International Journal of Nursing Studies, 50, 776-785. doi: 10.1016.j.ijnurstu.2012.07.002

Baron, R.M., \& Kenny, D.A. (1986). The moderator-mediator variable distinction in social psychology research: Conceptual, strategic, and statistical considerations. Journal of Personality and Social Psychology, 51(6), 1173-1182.

Blanchard, E., \& Jones-Alexander, J. (1996). Psychometric properties of the PTSD checklist (PCL). Behaviour Research \& Therapy, 34, 669.

Breslau, N., Lucia, V.C., \& Davis, G.C. (2004). Partial PTSD versus full PTSD: An empirical examination of associated impairment. Psychological Medicine, 34, 1205-1214.

Bullock, E.E., Braud, J., Andrews, L., \& Phillips, J. (2009). Career concerns of unemployed U.S. war veterans: Suggestions from a cognitive information processing approach. Journal of Employment Counseling, 46, 171-181.

Cook, J., Elhai, J., Cassidy, E., Ruzek, J., Ram, G., \& Sheikh, J. (2005). Assessment of trauma exposure and post-traumatic stress in long-term care veterans: Preliminary data on psychometrics and post-traumatic stress disorder prevalence. Military Medicine, 170, 862-866.

Coursol, D. H., Lewis, J., \& Garrity, L. (2001). Career development of trauma survivors: Expectations about counseling and career maturity. Journal of Employment Counseling, 38, 134-140. 
Delgado, C. (2007). Sense of coherence, spirituality, stress, and quality of life in chronic illness. Journal of Nursing Scholarship, 39, 229-234. doi: 10.1111/j.15475069.2007.00173.x

Dimidjian, S., \& Segal, Z.V. (2015). Prospects for a clinical science of mindfulnessbased intervention. American Psychologist, 70(7), 593-620. http://dx.doi.org/10.1037/a0039589

Dixon, L., Goldberg, R., Lehman, A., \& McNary, S. (2001). The impact of health status on work, symptoms, and functional outcomes in severe mental illness. The Journal Of Nervous And Mental Disease, 189(1), 17-23.

Dudek, B., \& Koniarek, J. (2000). Relationship between sense of coherence and posttraumatic stress disorder symptoms among firefighters. International Journal of Occupational Medicine and Environmental Health, 13, 299-305.

Erbes, C.R., Kaler, M.E., Schult, T., Polusny, M.A., \& Arbisi, P.A. (2011). Mental health diagnosis and occupational functioning in National Guard/Reserve veterans from Iraq. Journal of Rehabilitation Research \& Development, 48(10), 1159-1170.

Erbes, C., Westermeyer, J., Engdahl, B., \& Johnson, E. (2007). Post-traumatic stress disorder and service utilization in a sample of service members from Iraq and Afghanistan. Military Medicine, 172(4), 359-363.

Feldt, T., Leskinen, E., Kinnunen, U., \& Ruoppila, I. (2003). The stability of sense of coherence: Comparing two age groups in a 5-year follow-up study. Personality and Individual Differences, 35, 1151-1165. doi: 10.1016/S0191-8869(02)00325-2

Ferrajao, P.C., \& Oliveira, R.A. (2016). The effects of combat exposure, abusive violence, and sense of coherence on PTSD and depression in Portuguese Colonial 
War Veterans. Psychological Trauma: Theory, Research, Practice, and Policy, 8(1), 1-8. http://dx.doi.org/10.1037/tra0000043

Frazier, P.A., Tix, A.P., \& Barron, K.E. (2004). Testing moderator and mediator effects in counseling psychology research. Journal of Counseling Psychology, 51(1), 115-134. doi: 10.1037/0022-0167.51.1.115

Frenz, A.W., Carey, M.P., \& Jorgenson, R.S. (1993). Psychometric evaluation of Antonovsky's Sense of Coherence Scale. Psychological Assessment, 5(2), 145 153.

Gana, K. (2001). Is sense of coherence a mediator between adversity and psychological well-being in adults? Stress and Health, 17, 77-83.

Gewirtz, A.H., Polusny, M.A., DeGarmo, D.S., Khaylis, A., \& Erbes, C.R. (2010). Posttraumatic stress symptoms among National Guard soldiers deployed to Iraq: Associations with parenting behaviors and couple adjustment. Journal of Consulting and Clinical Psychology, 78(5), 599-610. doi: 10.1037/a0020571

Griffin, B., \& Hesketh, B. (2003). Adaptable Behaviours for Successful Work and Career Adjustment. Australian Journal of Psychology, 55(2), 65-73.

Haagen, J.F.G., Smid, G.E., Knipscheer, J.W., \& Kleber, R.J. (2015). The efficacy of recommended treatments for veterans with PTSD: A metaregression analysis. Clinical Psychology Review, 40, 184-194. http://dx.doi.org.lynx.lib.usm.edu/10.1016/j.cpr.2015.06.008

Hayes, A.F. (2009). Beyond Baron and Kenny: Statistical mediation analysis in the new millennium. Communication Monographs, 76(4), 408-420. doi: $10.1080 / 03637750903310360$ 
Haynie, J.M., \& Shepherd, D. (2011). Toward a theory of discontinuous career transition: Investigating career transitions necessitated by traumatic life events. Journal of Applied Psychology, 96(3), 501-524. doi: 10.1037/a0021450

Hirschi, A. (2012). Vocational identity trajectories: Differences in personality and development of well-being. European Journal of Personality, 26, 2-12. doi: $10.1002 /$ per. 812

Hirschi, A., \& Läge, D. (2007). Holland's secondary constructs of vocational interests and career choice readiness of secondary students: Measures for related but different constructs. Journal of Individual Differences, 28(4), 205-218. doi:10.1027/1614-0001.28.4.205

Hoge, C.W., Castro, C.A., Messer, S.C., McGurk, D., Cotting, D.I., \& Koffman, R.L. (2004). Combat duty in Iraq and Afghanistan, mental health problems, and barriers to care. New England Journal of Medicine, 351, 13-22. doi:

10.1056/NEJMoa040603

Hoge, C.W., Terhakopian, A., Castro, C.A., Messer, S.C., \& Engel, C.C. (2007). Association of posttraumatic stress disorder with somatic symptoms, health care visits, and absenteeism among Iraq War Veterans. American Journal of Psychiatry, 164, 150-153.

Hogh, A., \& Mikkelsen, E.G. (2005). Is sense of coherence a mediator or moderator of relationships between violence at work and stress reactions? Scandinavian Journal of Psychology, 46, 429-437

Holland, J.L., Daiger, D.C., \& Power, P.G. (1980). My Vocational Situation. Palo Alto, CA: Consulting Psychologists Press. 
Holland, J.L., Gottfredson, D.C., \& Power, P.G. (1980). Some diagnostic scales for research in decision making and personality: Identity, information, and barriers. Journal of Personality and Social Psychology, 39(6), 1191-1200.

Hourani, L., Bender, R.H., Weimer, B., Peeler, R., Bradshaw, M., Lane, M., \& Larson, G. (2012). Longitudinal study of resilience and mental health in marines leaving military service. Journal of Affective Disorders, 139, 154-165. doi: 10.1016/j.jad.2012.01.008

Jimmieson, N. L., \& Terry, D. J. (1998). An experimental study of the effects of work stress, work control, and task information on adjustment. Applied Psychology: An International Review, 47(3), 343-369. doi:10.1111/j.1464-0597.1998.tb00033.x

Joachim, B., Lyon, D.D., \& Farrell, S.P. (2003). Augmenting treatment of obsessivecompulsive disorder with Antonovsky's sense of coherence theory. Perspectives in Psychiatric Care, 39(4), 163-168.

Jordan, B.K., Marmar, C.R., Fairbank, J.A., Schlenger, W.E., Kulka, R.A., Hough, R., \& Weiss, D.S. (1992). Problems in families of male Vietnam veterans with posttraumatic stress disorder. Journal of Consulting and Clinical Psychology, 60(6), 916-926

Kahonen, K., Naatanen, Tolvanen, A., \& Salmela-Aro, K. (2012). Personality and Social Psychology: Development of sense of coherence during two group interventions. Scandinavian Journal of Psychology, 53, 523-527. Doi: 10.1111/sjop.12020

Keane, T.M. (2008). Posttraumatic stress disorder: Future directions in science and practice. Journal of Rehabilitation Research \& Development, 45(3), VII-IX. doi: 10.1682/JRRD.2008.05.0061 
Keen, S.M., Kutter, C.J., Niles, B.L., \& Krinsley, K.E. (2008). Psychometric properties of PTSD Checklist in sample of male veterans. Journal of Rehabilitation Research \& Development, 45(3), 465-474.

Kennedy, J.E., Leal, F.O., Lewis, J.D., Cullen, M.A., \& Amado, R.R. (2010). Posttraumatic stress symptoms in OIF/OEF service members with blast-related and non-blast-related mild TBI. Neuro Rehabilitation, 26, 223-231. doi: 10.3233/NRE-2010-0558

King, A.P., Erickson, T.M., Giardino, N.D., Favorite, T., Rauch, S.A.M., Robinson, E., Kulkami, M., \& Liberzon, I. (2013). A pilot study of group Mindfulness-Based Cognitive Therapy (MBCT) for combat veterans with posttraumatic stress disorder (PTSD). Depression \& Anxiety, 30(7), 638-645. doi: 10.1002/da.22104

Kivimaki, M., Vahtera, J., Elovainio, M., Lillirank, B., \& Kevin, M.V. (2002). Death or illness of a family member, violence, interpersonal conflict, and financial difficulties as predictors of sickness absence: Longitudinal cohort study on psychological and behavioral links. Psychosomatic Medicine, 64, 817-825.

Klepp, O.M., Mastekaasa, A., Sorenson, T., Sandanger, I., \& Kleiner, R. (2007). Structure analysis of Antonovsky's sense of coherence from an epidemiological mental health survey with a brief nine-item Sense of Coherence Scale. International Journal of Methods in Psychiatric Research, 16(1), 11-22.

Krantz, G., \& Ostergren, P.O. (2000). The association between violence victimization and common symptoms in Swedish women. Journal of Epidemiology and Community Health, 54, 815-821. 
Kroninger-Jungaberle, H., \& Grevenstein, D. (2013). Development of salutogenetic factors in mental health - Antonovsky's sense of coherence and Bandura's selfefficacy related to Derogatis' symptom checklist (SCL-90-R). Health and Quality of Life Outcomes, 11(80), 1-9. doi: 10.1186/1477-7525-11-80

Landrum, S.S. (2016). Enhancing recovery from trauma: Facilitating a mindfulness skills group on a Department of Veterans Affairs inpatient PTSD unit. Social Work with Groups, 39(1), 35-47. Doi: 10.1080/01609513.2014.999203

Langeland, E., Riise, T., Hanestad, B.R., Nortvedt, M.W., Kristoffersen, K., \& Wahl, A.K. (2006). The effect of salutogenic treatment principles on coping with mental health problems: A randomized controlled trial. Patient Education and Counseling, 62, 212-219.

Lapierre, C.B., Schwegler, A.F., \& LaBauve, B.J. (2007). Posttraumatic stress and depression symptoms in soldiers returning from combat operations in Iraq and Afghanistan. Journal of Traumatic Stress, 20(6), 933-943. doi: 10.1002/jts.20278

Lustig D.C., \& Strauser, D.R. (2002). The relationship between sense of coherence and career thoughts. The Career Development Quarterly, 51, 2-11.

Lustig, D.C., Strauser, D.R., Detrie, P., Henderson, D., \& Frazier, N. (2001). The relationship between sense of coherence and work personality and career thoughts. Paper presented at the 2001 American Counseling Association Conference, San Antonio, TX.

Marzabadi, E.A., \& Hashem Zadeh, S.M. (2014). The effectiveness of mindfulness training in improving the quality of life of the war victims with post traumatic stress disorder (PTSD). Iranian Journal of Psychiatry, 9(4), 228-236. 
Mauer, E. B., \& Gysbers, N. C. (1990). Identifying career concerns of entering university freshmen using My Vocational Situation. Career Development Quarterly, 39(2), 155.

Michon, H., ten Have, M., Kroon, H., van Weeghel, J., de Graaf, R., \& Schene, A. (2008). Mental disorders and personality traits as determinants of impaired work functioning. Psychological Medicine, 38(11), 1627-1637. doi:

$10.1017 / \mathrm{S} 0033291707002449$

Milliken, C.S., Auchterlonie, J.L., \& Hoge, C.W. (2007). Longitudinal assessment of mental health problems among active and reserve component soldiers returning from the Iraq war. Journal of the American Medical Association, 298(18), 21412148.

Moksnes, U.K., Lohre, A., \& Espnes, G.A. (2013). The association between sense of coherence and life satisfaction in adolescents. Quality Life Research, 22, 13311338. doi: 10.1007/s11136-012-0249-9

Murdoch, M., Pryor, J.N., Polusny, M.A., \& Gackstetter, G.D. (2007). Functioning and psychiatric symptoms among military men and women exposed to sexual stressors. Military Medicine, 172, 718-725.

Niessen, C., Binnewies, C., \& Rank, J. (2010). Disengagement in work-role transitions. Journal of Occupational and Organizational Psychology, 83, 695-715. doi: $10.1348 / 096317909 X 470717$

Niles, B.L., Klunk-Gillis, J., Ryngala, D.J., Silberbogen, A.K., Paysnick, A., \& Wolf, E.J. (2012). Comparing mindfulness and psychoeducation treatments for combatrelated PTSD using a telehealth approach, Psychological Trauma: Theory, 
Research, Practice, and Policy, 4(5), 538-547.

http://dx.doi.org.lynx.lib.usm.edu/10.1037/a0026161

Osborne, L.K., \& Bullock-Yowell, E. (2011). Does college ROTC stabilize your career path? Poster session presented at the meeting of the Society for Vocational Psychology, Boston, MA.

Possemato, K., Bergen-Cico, D., Treatman, S., Allen, C., Wade, M., \& Pigeon, W. (2016). A randomized clinical trial of primary care brief mindfulness training for veterans with PTSD. Journal of Clinical Psychology, 72(3), 179-193 http://dx.doi.org.lynx.lib.usm.edu/10.1002/jclp.22241

Pietrzak, R.H., Goldstein, M.B., Malley, J.C., Rivers, A.J., Johnson, D.C., Morgan, C.A., \& Southwick, S.M. (2010). Posttraumatic growth in veterans of Operations Enduring Freedom and Iraqi Freedom. Journal of Affective Disorders, 126, 230235. doi: $10.1016 /$ j.jad2010.03.021

Pietrzak, R.H., Johnson, D.C., Goldstein, M.B., Malley, J.C., Rivers, A.J., Morgan, C.A., \& Southwick, S.M. (2010). Psychosocial buffers of traumatic stress, depressive symptoms, and psychosocial difficulties in veterans of Operations Enduring Freedom and Iraqi Freedom: The role of resilience, unit support, and postdeployment social support. Journal of Affective Disorders, 120, 188-192. doi: 10.1016/j.jad.2009.04.015

Pietrzak, R.H., \& Southwick, S.M. (2011). Psychological resilience in OEF-OIF Veterans: Application of a novel classification approach and examination of demographic and psychosocial correlates. Journal of Affective Behaviors, 133, 560-568. doi: 10.1016/j.jad.2011.04.028 
Power, P.W., \& Hershenson, D.B. (2003). Work adjustment and readjustment of persons with mid-career onset traumatic brain injury. Brain Injury, 17(12), 1021-1034. doi: $10.1080 / 0269905031000110526$

Renshaw, K.D. (2011). An integrated model of risk and protective factors for postdeployment PTSD symptoms in OEF/OIF era combat veterans. Journal of Affective Disorders, 128, 321-326. doi:10.1016/j.jad.2010.07.022

Resnick, S.G., \& Rosenheck, R.A. (2008). Posttraumatic stress disorder and employment in veterans participating in Veterans Health Administration compensated work therapy. Journal of Rehabilitation Research \& Development, 45(3), 427-436.

Rona, R.J., Jones, M., Iversen, A., Hull, L., Greenberg, N., Fear, N.T., Hotopf, M., \& Wessely, S. (2009). The impact of posttraumatic stress disorder on impairment in the UK military at the time of the Iraq War. Journal of Psychiatric Research, 43, 649-655. doi: 10.1016/j.jpsychires.2008.09.006

Rosenfeld, J.V., McFarlane, A.C., Bragge, P., Armonda, R.A., Grimes, J.B., \& Ling, G.S. (2013). Blast-related traumatic brain injury. Lancet Neurol, 12, 882-893. doi: $10.1016 / \mathrm{S} 1474.44422(13) 70161-3$

Rudstam, H., Gower, W.S., \& Cook, L. (2012). Beyond yellow ribbons: Are employers prepared to hire, accommodate and retain returning veterans with disabilities? Journal of Vocational Rehabilitation, 36, 87-95. doi: 10.3233/JVR-2012-0584

Sarenmalm, E.K., Browall, M., Persson, L.O., Dall-Dickson, J., \& Gaston-Johansson, F. (2013). Relationship of sense of coherence to stressful events, coping strategies, health status, and quality of life in women with breast cancer. Psycho-Oncology, 22, 20-27. doi: 10.1002/pon.2053 
Schnurr, P.P., Lunney, C.A., Bovin, M.J., \& Marx, B.P. (2009). Posttraumatic stress disorder and quality of life: Extension of findings to veterans of the wars in Iraq and Afghanistan. Clinical Psychology Review, 29, 727-735. doi:

10.1016/j.cor.2009.08.006

Schnyder, U., Buchi, S., Sensky, T., \& Klaghofer, R. (2000). Antonovsky’s sense of coherence: trait or state? Psychotherapy and Psychosomatics, 69(2), 296-302.

Secker, J., Membrey, H., Grove, B., \& Seebohm, P. (2003). The how and why of workplace adjustments: Contextualizing the evidence. Psychiatric Rehabilitation Journal, 27(1), 3-9. doi:10.2975/27.2003.3.9

Shin, Y., \& Kelly, K.R. (2013). Cross-cultural comparison of the effects of optimism, intrinsic motivation, and family relations on vocational identity. The Career Development Quarterly, 61, 141-160. doi: 10.1002/j.2161-0045.2013.00043.x

Smith, M.W., Schnurr, P.P., Rosenheck, R.A., \& Salzer, M. (2005). Employment outcomes and PTSD symptom severity. Mental Health Services Research, 7(2), 89-101. doi: 10.1007/s11020-005-3780-2

Spiegel, P. E., \& Shultz, K. S. (2003). The Influence of Preretirement Planning and Transferability of Skills on Naval Officers' Retirement Satisfaction and Adjustment. Military Psychology, 15(4), 285-307. doi:

10.1207/S15327876MP1504_3

Steenkamp, M.M., Litz, B.T., Hoge, C.W., \& Marmar, C.R. (2015). Psychotherapy for military-related PTSD: A review of randomized clinical trials. Journal of the American Medical Association, 314(5), 489-500.

http://dx.doi.org.lynx.lib.usm.edu/10.1001/jama.2015.8370 
Stein, M.B., McQuaid, J.R., Pedrelli, P., Lenox, R., \& McCahill, M.E. (2000).

Posttraumatic stress disorder in the primary care medical setting. General Hospital Psychiatry, 22, 261-269.

Stewart, J. (1994). Counseling individuals who experience career decision-making difficulties. Guidance \& Counseling, 9(4), 11-14.

Strauser, D. R., \& Lustig, D. C. (2003). The moderating effect of sense of coherence on work adjustment. Journal of Employment Counseling, 40(3), 129-140.

Strauser, D.R., Lustig, D.C., \& Ciftci, A. (2008). Psychological well-being: It's relation to work personality, vocational identity, and career thoughts. The Journal of Psychology, 142(1), 21-35.

Strauser, D.R., Lustig, D.C., Cogdal, P.A., \& Uruk, A.C. (2006). Trauma symptoms: Relationship with career thoughts, vocational identity, and developmental work personality. The Career Development Quarterly, 54, 346-360.

Streb, M., Haller, P., \& Michael, T. (2014). PTSD in paramedics: Resilience and sense of coherence. Behavioural and Cognitive Psychotherapy, 42(4), 452-463. http://dx.doi.org.lynx.lib.usm.edu/10.1017/S1352465813000337

Sullivan, G.C. (1993). Towards clarification of convergent concepts: Sense of coherence, will to meaning, locus of control, learned helplessness, and hardiness. Journal of Advanced Nursing, 18, 1772-1778.

Switaj, P., Anczewska, M., Chrostek, A., Grygiel, P., Prot-Klinger, K., Choma, M., \& Wciorka, J. (2013). The sense of coherence as a predictor of the scope and impact of stigma experiences among people with mental illness. Psychiatry Research, 209, 249-251. doi: 10.1016/j.psychres.2013.04.018 
U.S. Department of Labor. (2016). Employment status of the civilian population 18 years and over by veteran status, period of service, and sex, not seasonally adjusted. Retrieved April 15, 2016 from http://www.bls.gov/news.release/archives/empsit_04012016.htm

Veronese, G., \& Alessandro, P. (2014). Sense of coherence mediates the effect of trauma on the social and emotional functioning of Palestinian health providers. American Journal of Orthopsychiatry, 84(5), 597-606.

http://dx.doi.org/10.1037/ort0000025

Vondracek, F. W. (1992). The construct of identity and its use in career theory and research. Career Development Quarterly, 41(2), 130-144.

Vossler, A. (2012). Salutogenesis and the sense of coherence: Promoting health and resilience in counseling and psychotherapy. Counselling Psychology Review, 27(3), 68-78.

Wallner, R. J., \& Clark, D. W. (1989). The Functional Assessment Inventory and job tenure for persons with severe and persistent mental health problems. Journal of Applied Rehabilitation Counseling, 20(4), 13-15.

Weathers, F.W., Litz, B.T., Herman, D.S., Huska, J.A., \& Keane, T.M. (1993). The PTSD checklist (PCL): Reliability, validity, and diagnostic utility. Paper presented at the Annual Meeting of the International Society for Traumatic Stress Studies, San Antonio, TX. Retrieved from www.pdhealth.mil/library/downloads/PCL_psychometrics.doc

Weissman, M.M. (1999). Social Adjustment Scale-Self-Report. North Tonawanda, NY: Multi-Health Systems Inc. 
Weissman, M.M., Olfson, M., Gameroff M.J., Feder, A., \& Fuentes, M. (2001). A comparison of three scales for assessing social functioning in primary care. American Journal of Psychiatry, 158(3), 460-466. doi:

10/1176/appi.ajp.158.3.460

Wiesmann, U., \& Hannich, H.J. (2013). The contribution of resistance resources and sense of coherence to life satisfaction in older age. Journal of Happiness Studies, 14, 911-928. doi: 10.1007/s10902-012-9361-3

Zeidner, M., \& Aharoni-David, E. (2015). Memories of Holocaust-related traumatic experiences, sense of coherence, and survivors' subjective well-being in late life: Some puzzling findings. Anxiety, Stress \& Coping: An International Journal, 28(3), 257-271.

http://dx.doi.org.lynx.lib.usm.edu/10.1080/10615806.2014.954244

Zivin, K., Campbell, D.G., Lanto, A.B., Chancey, E.F., Bolkan, C., Bonner, L.M., Miller, E.M., Valenstein, M., Waltz, T.J., \& Rubenstein, L.V. (2012). Relationships between mood and employment over time among depressed VA primary care patients. General Hospital Psychiatry, 34, 468-477. doi:

10.1016/j.genhosppsych.2012.05.008 